\title{
Genetic control of yield and yield components in winter oilseed rape (Brassica napus L.) grown under nitrogen limitation
}

\author{
Anne-Sophie Bouchet • Nathalie Nesi • Christine Bissuel • \\ Michel Bregeon - Amandine Lariepe $\cdot$ Hélène Navier • \\ Nicolas Ribière $\cdot$ Mathilde Orsel $\cdot$ Bruno Grezes-Besset • \\ Michel Renard $\cdot$ Anne Laperche
}

Received: 16 December 2013/Accepted: 21 April 2014/Published online: 8 May 2014

(C) The Author(s) 2014. This article is published with open access at Springerlink.com

\begin{abstract}
Despite its high nitrogen absorption capacity, oilseed rape (OSR) has a low apparent nitrogen use efficiency (NUE), which makes its production highly dependent on nitrogen fertilization. Improving NUE in OSR is therefore a main target in breeding. The objectives of the present work were to determine the genomic regions (QTLs) associated with yield and to assess their stability under contrasted nitrogen nutrition regimes. One mapping population, AM, was tested in a French location for three growing seasons (2011, 2012 and 2013), under two nitrogen
\end{abstract}

Electronic supplementary material The online version of this article (doi:10.1007/s10681-014-1130-4) contains supplementary material, which is available to authorized users.

A.-S. Bouchet · N. Nesi $(\bowtie) \cdot$ M. Bregeon ·

H. Navier · M. Orsel · M. Renard

INRA, UMR1349 IGEPP, BP 35327, 35650 Le Rheu,

France

e-mail: nathalie.nesi@rennes.inra.fr

C. Bissuel · A. Laperche

AGROCAMPUS OUEST, UMR1349 IGEPP, BP 35327 ,

35650 Le Rheu, France

A. Lariepe · N. Ribière - B. Grezes-Besset

Biogemma, Chemin de Panedautes, Domaine de

Sandreau, 31700 Mondonville, France

Present Address:

M. Orsel

INRA, UMR IRHS, 42 rue Georges Morel,

49071 Beaucouzé, France conditions (optimal and low). Eight yield-related traits were scored and nitrogen-responsive traits were calculated. A total of 104 QTLs were detected of which 28 controlled flowering time and 76 were related to yield and yield components. Very few genotype $\times$ nitrogen interactions were detected and the QTLs were highly stable between the nitrogen conditions. In contrast, only a few QTLs were stable across the years of the trial, suggesting a strong QTL $\times$ year interaction. Finally, eleven critical genomic regions that were stable across nitrogen conditions and/or trial years were identified. One particular region located on the A5 linkage group appears to be a promising candidate for marker assisted selection programs. The different strategies for OSR breeding using the QTLs found in the present study are discussed.

Keywords Rapeseed - Nitrogen use efficiency · Nitrogen stress · Yield components · Quantitative trait locus $\cdot \mathrm{G} \times \mathrm{E}$ interactions
Abbreviation
AM Aviso $\times$ Montego population
DH Doubled haploid
DTF Days to flowering
GDD Growing degree day
GFP Grain filling period
LG Linkage group
LR11 Le Rheu trial in 2010-2011 season
LR12 Le Rheu trial in 2011-2012 season 
LR13 Le Rheu trial in 2012-2013 season

$\mathrm{N} \quad$ Nitrogen

NNI Nitrogen nutrition index

NUE Nitrogen use efficiency

O Seed oil content

OSR Oilseed rape

OY Oil yield

Pr Seed protein content

PrY Protein yield

QTL Quantitative trait locus

SN Seed number per $\mathrm{m}^{2}$

SY Seed yield

TSW Thousand seed weight

\section{Introduction}

The use of inorganic nitrogen $(\mathrm{N})$ was a key driver of the Green Revolution in the mid-twentieth century and helped to dramatically improve the yields of major crops. Worldwide, the use of $\mathrm{N}$ fertilizers increased by $430 \%$ from 1965 to 1998 (Mosier 2002) and new varieties were selected for their ability to respond to high $\mathrm{N}$ inputs and in particular for their improved resistance to lodging. However, massive fertilization has major environmental drawbacks, with nitrate leaching and greenhouse gas emissions, resulting in water and air pollution (Hirel et al. 2011). In addition, the high cost of $\mathrm{N}$ fertilizer also has a significant impact on farmer incomes. Therefore, reducing $\mathrm{N}$ inputs is a major issue for achieving sustainable agriculture at the agronomic, environmental and economic level in the future.

Oilseed rape (OSR) is a crop of high economic value, with Canada (15.4 MT in 2012; 1,840 kg/ha), China (14 MT; 1,920 kg/ha), France (5.4 MT; $3,400 \mathrm{~kg} / \mathrm{ha}$ ) and Germany (4.8 MT; 3,700 kg/ha) as the main producers (FAOSTAT 2012). It is grown mainly for its oil-rich seeds $(\sim 40-45 \%$ of the seed dry matter) used for human consumption and in industrial applications. The seed cake contains $\sim 30-35 \%$ protein and is used as animal feed. Thus, grain yield as well as increased seed oil and protein are major targets for breeding programs.

$\mathrm{N}$ use efficiency (NUE), which is the seed yield achieved per $\mathrm{N}$ unit available to the crop, is the product of two components: the $\mathrm{N}$ uptake efficiency (NUpE), the proportion of available $\mathrm{N}$ that is taken up by the crop, and the $\mathrm{N}$ utilization efficiency (NUtE), the grain yield achieved by $\mathrm{N}$ unit absorbed by the crop (Moll et al. 1982). Compared to other crops, OSR has a low apparent NUE [15.3 kg seed/kg available $\mathrm{N}$ vs. $35-40 \mathrm{~kg} / \mathrm{kg}$ for cereals (CETIOM 2011)]. This is partly due to the higher energy content of OSR seeds compared to cereals grains. Potential improvements of NUE in OSR would include optimisation of traits related to $\mathrm{NUpE}$ (e.g., rooting traits, duration of $\mathrm{N}$ uptake, total $\mathrm{N}$ accumulated during vegetative growth) as well as NUtE (e.g., $\mathrm{N}$ remobilization during leaf senescence, increased harvest index).

However, although NUE improvement has been considered as a major goal (Yau and Thurling 1987; Rathke et al. 2006; Schulte auf'm Erley et al. 2007; Berry et al. 2010; Miro 2010; Kessel et al. 2012), no varieties have been specifically generated to address this issue as yet, with the exception of a genetically modified OSR line overexpressing the barley alanine aminotransferase gene in the roots (Good et al. 2007). Therefore, better knowledge of the genetic adaptation of OSR to $\mathrm{N}$ constraints is needed. Unravelling the genetic control of the traits contributing to the yield of OSR grown under low $\mathrm{N}$ input is a way to improve NUE and to propose new $\mathrm{N}$-efficient OSR cultivars (Brancourt-Hulmel et al. 2005; Berry et al. 2010). This will lead to (1) improved knowledge of the allelic diversity and the genetic and molecular determinism of yield and yield components under low $\mathrm{N}$ constraints and (2) optimal allele mining for pre-breeding.

Grain yield is a very complex trait in OSR compared to other crops. The complexity is mainly related to the potential of OSR for growth and branching after flowering which enable the crop to use one yield component to compensate for limitations in another one. As a consequence, a given final yield can result from different combinations of yield components (number of plants per $\mathrm{m}^{2}$, number of pods per plant, seed weight, seed quality...) (Diepenbrock 2000). All these components are impacted by developmental traits (flowering time, seed filling duration), and environmental conditions (climatic conditions, water and fertilizer availability). These traits are all under polygenic control and previous analyses identified several quantitative trait loci (QTLs) for seed oil content (Ecke et al. 1995; Gül 2002; Burns et al. 2003; Delourme et al. 2006; Qiu 
et al. 2006; Zhao et al. 2006; Mei et al. 2009; Zou et al. 2010), seed yield (Udall et al. 2006; Radoev et al. 2008; Basunanda et al. 2010; Chen et al. 2010), plant height (Basunanda et al. 2010), thousand seed weight (Basunanda et al. 2010; Ding et al. 2012), number of seeds per area (Ding et al. 2012), number of pods per area (Radoev et al. 2008) and flowering time (Chen et al. 2010; Honsdorf et al. 2010). However, only a small number of studies were carried out under abiotic stress, such as cold stress (Kole et al. 2002; Asghari et al. 2007), boron stress (Xu et al. 2001) or phosphorus stress (Yang et al. 2010; Ding et al. 2012). In the context of N stress, QTL analyses have been performed on major cereal crops, including barley (Kjaer and Jensen 1995; Gorny and Sodkiewicz 2001; Mickelson et al. 2003), maize (Hirel et al. 2001; Coque et al. 2008), rice (Lian et al. 2005; Cho et al. 2007) and wheat (Habash et al. 2007; Laperche et al. 2007) whereas there have been a couple of studies carried out on OSR (Gül 2002, Miro 2010).

The aim of the present study was to extend our knowledge of the genetic control of yield and its components under $\mathrm{N}$ constraints. For this, a genetic analysis of yield components in a winter OSR segregating population grown under two contrasting $\mathrm{N}$ conditions was undertaken. Our objectives were to (1) determine the main genomic regions(s) involved in yield and its components, (2) understand the organization of the intricate network of QTLs in the Brassica napus genome, and (3) assess their stability over years and contrasting $\mathrm{N}$ nutrition regimes in order to identify the regions with potential for use in breeding programs.

\section{Materials and methods}

Plant material and genetic map

A population of 112 doubled haploid (DH) lines was derived from an Aviso $\times$ Montego (AM) cross. The parental lines were chosen for their contrasted yield response to a change in the $\mathrm{N}$ nutrition regime: Aviso uses $\mathrm{N}$ more effectively for yield and shows a smaller difference in seed yield between the two $\mathrm{N}$ regimes than Montego (unpublished results). The parental lines were used as controls in the trials. The AM genetic map was described by Delourme et al. (2013) and comprises 2301 SNPs representing 831 unique loci, covering a total length of $1,947.3 \mathrm{cM}$, at a density of one marker every $2.34 \mathrm{cM}$. Chi square tests for goodness of fit $(1: 1 ; p$ value $=0.01)$ on the 2301 SNPs revealed that $20.6 \%$ of the markers were in segregation distortion at the whole genome level. The linkage groups (LGs) with the highest proportion of loci in distortion were A2 (99.5\%), A7 (35.3\%), C5 (71.4\%) and C9 (86\%).

Field trials and trait measurements

The AM population was evaluated in Le Rheu (LR) located in Brittany (France) during the 2010-2011 $\left(48^{\circ} 8^{\prime} 21.63^{\prime \prime} \mathrm{N}-1^{\circ} 48^{\prime} 9.26^{\prime \prime} \mathrm{O}\right), 2011-2012 \quad\left(48^{\circ} 8^{\prime} 31\right.$. $\left.77^{\prime \prime} \mathrm{N}-1^{\circ} 46^{\prime} 59.76^{\prime \prime} \mathrm{O}\right)$ and 2012-2013 (48 $8^{\prime} 21.76^{\prime \prime} \mathrm{N}-$ $\left.1^{\circ} 46^{\prime} 56.23^{\prime \prime} \mathrm{O}\right)$ cropping seasons. The LR station has a deep loamy soil (58\% silt, $24 \%$ sand, $18 \%$ clay, and depth $>80 \mathrm{~cm})$. Plants were grown under two $\mathrm{N}$ regimes (N1: low; N2: optimal) as described in detail below. In order to limit the amount of mineral $\mathrm{N}$ in soil in the experimental plots, no organic matter was spread on the fields for 3 years before the trials and the previous crops were grown under a low input management system (see Supplementary Data S1a).

\section{Experimental design}

All trials were designed as split-plots with $\mathrm{N}$ as the main plots and genotypes as subplots. The 2010-2011 trial (hereafter referred to as LR11) involved three replicates. The 2011-2012 and 2012-2013 trials (hereafter referred to as LR12 and LR13 respectively) involved four replicates. Plants were sown in $10.5 \mathrm{~m}^{2}$ plots at a density of 45 seeds $/ \mathrm{m}^{2}$. Plants were sown in early-to-mid September and the entire plots were harvested at the beginning-to-mid July. Details of the crop management strategy used in LR11, LR12 and LR13 are shown in Supplementary Data S1b. In order to estimate the $\mathrm{N}$ mineralization and leaching, extra plots that were kept empty of plants were added on the borders of the experimental plots.

\section{Characterization of the crop sites}

Several soil and climatic variables were recorded throughout the crop cycle. The mineral $\mathrm{N}$ soil content was measured for each control under both $\mathrm{N}$ conditions and on the extra plots empty of plants at three dates: just before sowing, at the end of winter and after the seed 
harvest. Homogeneous samples of soil $(50 \mathrm{~g})$ were collected for three horizons (0-30, 30-60, 60-90 cm). Mineral $\mathrm{N}$ was estimated using the Kjeldahl method (Kjeldahl 1883) $\left(\mathrm{NO}^{3-}\right.$ and $\mathrm{NH}^{4+}$ ions were scored separately). The $\mathrm{N}$ soil values were used to calculate the required $\mathrm{N}$ fertilization (see Eq. 1).

Daily air temperature (in ${ }^{\circ} \mathrm{C}$ ), rainfall (in $\mathrm{mm}$ ), global radiation (in $\mathrm{J} / \mathrm{cm}^{2}$ ) and Penmann evapotranspiration (in $\mathrm{mm}$ ) were recorded throughout the whole crop cycle by the INRA meteorological station located at Le Rheu and endorsed by Météo France (station no 35240001). These data identified four climatic periods: autumn, winter, spring and grain filling period (GFP). The autumn period started with the sowing and ended on the first day that the air temperature was below $0{ }^{\circ} \mathrm{C}$. The winter period lasted as long as the daily mean air temperature was below $0{ }^{\circ} \mathrm{C}$. The spring period extended from the end of winter to the beginning of flowering, which was calculated as the mean of the flowering date for all the genotypes. Flowering was defined as $50 \%$ of the plants showing $10 \%$ open flowers on the primary inflorescence, defined as the 61 stage according to the $\mathrm{BBCH}$ scale for OSR (Lancashire et al. 1991). Finally, the GFP lasted from the beginning of flowering until seed harvest. For each period, the values of the cumulated temperatures (growing degree day, GDD), cumulated rainfalls (in $\mathrm{mm}$ ), cumulated global radiation (in $\mathrm{MJ} / \mathrm{m}^{2}$ ) and cumulated Penmann evapotranspiration (in $\mathrm{mm}$ ) were calculated.

\section{Management of $N$ fertilization}

$\mathrm{N}$ fertilization was calculated using the balance sheet method that is commonly used in France for the main arable crops (Rémy and Hébert 1977; Parnaudeau et al. 2009). The $\mathrm{N}$ doses were calculated as follows:

$X=[(6.5 \times S Y)-R i+R f-P i-M n)]$

where $S Y$ is the yield objective (defined in our study at $3.5 \mathrm{t} / \mathrm{ha}$ for $\mathrm{N} 2$ and $2.0 \mathrm{t} / \mathrm{ha}$ for $\mathrm{N} 1$ ), $R i$ is the mineral $\mathrm{N}$ soil amount measured at the end of winter (as described above), $R f$ is the mineral $\mathrm{N}$ soil amount at seed harvest (estimated at $30 \mathrm{~kg} \mathrm{~N} /$ ha for deep loamy soils in Brittany according to the CETIOM reference values), $P i$ is the amount of $\mathrm{N}$ absorbed by the plants at the end of winter (determined as described below) and $M n$ is the estimated amount of $\mathrm{N}$ mineralized during spring from the soil organic matter (estimated at
$50 \mathrm{~kg} / \mathrm{ha}$ according to the CETIOM). The $\mathrm{N} 1$ regime corresponded to $40 \mathrm{~kg} \mathrm{~N} / \mathrm{ha}$ for LR11 and $0 \mathrm{~kg} \mathrm{~N} / \mathrm{ha}$ for LR12 and LR13. The N2 regime corresponded to $130 \mathrm{~kg} \mathrm{~N} / \mathrm{ha}$ for LR11 and to $80 \mathrm{~kg} \mathrm{~N} / \mathrm{ha}$ for LR12 and LR13. All applications were made using liquid fertilizer with a $39 \% \mathrm{~N}$ solution $(50 \%$ urea, $25 \%$ nitrate and $25 \%$ ammonium) at two dates (the beginning of stem elongation and during spring elongation) as recommended for OSR crop management in Brittany. In this region, autumnal mineralization is sufficient to cover rapeseed $\mathrm{N}$ needs until the start of stem elongation, avoiding fertilizing during that period. Indeed, at the end of winter, the amount of $\mathrm{N}$ soil in the $0-90 \mathrm{~cm}$ profile ranged from 54 to $143.4 \mathrm{~kg} / \mathrm{ha}$ under empty plots and from 11 to $52.5 \mathrm{~kg} / \mathrm{ha}$ under the plots with plants (Supplementary Data S1c), reflecting huge amounts of $\mathrm{N}$ available in the soil at this period and a high $\mathrm{N}$ absorption by the plants.

The $\mathrm{N}$ nutrition index (NNI) was measured on the controls at the end of autumn (date 1), the end of winter (date 2) and during spring elongation (date 3). At dates 1 and 2, no $\mathrm{N}$ fertilizer had been applied yet, so all the plants were at the same $\mathrm{N}$ nutrition level. A surface of $1 \mathrm{~m}^{2}$ was harvested and above ground plant tissue was directly weighed to determine the fresh matter weights then dried $\left(70{ }^{\circ} \mathrm{C} \mathrm{o} / \mathrm{n}\right)$ for dry matter measurements and finally ground and used to estimate the $\mathrm{N}$ content using the Dumas combustion method. The NNI values were then calculated according to Colnenne et al. 1998. The plants were considered stressed if the NNI values were below 0.8 (Colnenne et al. 1998). A $t$ test was performed to compare the NNI values at date 3 between the $\mathrm{N}$ conditions.

\section{Trait measurements}

The traits measured were as follows. The days to flowering (DTF in days) was the number of days from the 1st January until the day when $50 \%$ of the plants showed $10 \%$ of open flowers on the primary inflorescence. The seed yield ( $S Y$ in $\mathrm{t} / \mathrm{ha}$ ) was determined for each plot from a sample of $200 \mathrm{~g}$ of seeds, adjusted to $0 \%$ water content and $0 \%$ impurities. The thousand seed weight (TSW in g) was determined by weighing and counting an aliquot of fully dried seeds. The seed oil content ( $O$ in $\%$ of the seed dry matter) and the seed protein content ( $P r$ in $\%$ of the seed dry matter) were estimated using near-infrared reflectance spectroscopy (Foss 6500 NIRS equipment) using 
commercial calibrations developed for OSR (P. Dardenne, Univ. Gembloux, Belgium; equation \#5colz38.eqa). In addition, oil yield $(O Y=O \times S Y$, in $\mathrm{t} / \mathrm{ha})$, protein yield $(\operatorname{Pr} Y=\operatorname{Pr} \times S Y$, in $\mathrm{t} / \mathrm{ha})$ and the seed number $/ m^{2}(S N=(S Y \times 100000) / T S W)$ were calculated. In order to evaluate the response of the genotypes to a change in $\mathrm{N}$ regime, a number of ratios with values obtained under $\mathrm{N} 1$ and $\mathrm{N} 2$ nutrition levels were calculated for the seed yield, the seed number $/ \mathrm{m}^{2}$, and the oil yield and protein yield traits. The ratio (N1/N2) estimated the deviation from the linear relationship between $\mathrm{N} 1$ and $\mathrm{N} 2$ (Laperche et al. 2007). The term $(\Delta N / N 2$, where $\Delta N=N 2-N 1)$ expressed the QTL $\times \mathrm{N}$ interaction adjusted to the value of the trait under optimal fertilization conditions (N2).

Phenotype data analysis

All statistical analyses, including QTL analyses, were carried out with R software (RCoreTeam 2013). The different mixed models were analyzed using the lme4 package (Bates et al. 2013).

A combined mixed linear model was fitted on the $112 \mathrm{DH}$ lines and the parents for each trait $(\mathrm{P})$ using the REML method, with all 3 years combined.

$$
\begin{aligned}
P_{i j k l}= & \mu+G_{i}+N_{j}+Y_{l}+G_{i} \times N_{j}+Y_{l}\left(R_{k}\right)+G_{i} \\
& \times Y_{l}+e_{i j k l m}
\end{aligned}
$$

where $P_{\mathrm{ijkl}}$ is the phenotypic value, $\mu$ is the population mean, $G_{i}$ stands for the genotype i, $N_{j}$ for the $\mathrm{N}$ nutrition condition $\mathrm{j}, R_{k}$ for the replicate $\mathrm{k}$ and $Y_{l}$ for the year 1 and $e_{i j k l m}$ is the residual.

To test for genotype $(\mathrm{G}), \mathrm{N}$ nutrition condition $(\mathrm{N})$, year $(\mathrm{Y})$, genotype $\times$ year $(\mathrm{G} \times \mathrm{Y})$ and genotype $\times N(G \times N)$ effects, these terms were first considered as fixed. The replicate $(\mathrm{R})$ was considered random. In a second model, we considered only $N_{j}$ as the fixed term, in order to estimate $\mathrm{G}, \mathrm{Y}, \mathrm{G} \times \mathrm{N}$ and $\mathrm{G} \times \mathrm{Y}$ variances.

Based on the model 2, broad sense heritability was then calculated as:

$$
h^{2}=\frac{\sigma_{G}^{2}}{\sigma_{G}^{2}+\frac{\sigma_{G \times N}^{2}}{n}+\frac{\sigma_{G \times Y}^{2}}{y}+\frac{\sigma_{e}^{2}}{y \times n \times r}}
$$

where $\sigma_{G}^{2}$ is the genetic variance, $\sigma_{G \times N}^{2}$ the $\mathrm{G} \times \mathrm{N}$ variance, $\sigma_{e}^{2}$ the residual variance, $\sigma_{G \times Y}^{2}$ the $\mathrm{G} \times \mathrm{Y}$ variance, $\mathrm{n}$ the number of $\mathrm{N}$ conditions, $\mathrm{y}$ the number of years, and $\mathrm{r}$ the number of replicates per genotype per $\mathrm{N}$ and per year.

A second mixed linear model was applied to each year.

$P_{i j k l}=\mu+G_{i}+N_{j}+R_{k}+G_{i} \times N_{l}+e_{i j k l}$

where $P_{\mathrm{ijkl}}$ is the phenotypic value, $\mu$ is the population mean, $G_{i}$ stands for the genotype i, $N_{j}$ for the $\mathrm{N}$ nutrition condition $\mathrm{j}, R_{k}$ for the replicate $\mathrm{k}$ and $e_{i j k l}$ is the residual. $\mathrm{R}$ was considered random and $\mathrm{G}, \mathrm{N}$ and $\mathrm{G} \times \mathrm{N}$ were tested as for model 2 .

The corresponding heritabilities were assessed as follows:

$h^{2}=\frac{\sigma_{G}^{2}}{\sigma_{G}^{2}+\frac{\sigma_{G \times N}^{2}}{n}+\frac{\sigma_{e}^{2}}{n \times r}}$

A last mixed linear model was applied to each year $\times \mathrm{N}$ combination:

$P_{i j k l}=\mu+G_{i}+R_{k}+e_{i j k}$

where $P_{\mathrm{ijkl}}$ is the phenotypic value, $\mu$ is the population mean, $G_{i}$ stands for the genotype i, $R_{k}$ for the replicate $\mathrm{k}$ and $e_{\mathrm{ijk}}$ for the residual. All terms were declared as random. The heritabilities were estimated for each $\mathrm{N}$ condition and each year with the following formula:

$h^{2}=\frac{\sigma_{G}^{2}}{\sigma_{G}^{2}+\frac{\sigma_{e}^{2}}{r}}$

The Pearson's correlation coefficients between the different traits were also calculated.

Linkage analysis: multiple QTL mapping (MQM)

A multiple QTL mapping model was tested using the R/qtl package (Broman et al. 2003) for each trait in each year $\times \mathrm{N}$ combination and for each $\mathrm{N}$-responsive trait on the 2301 SNPs. For each trait and each genotype, the adjusted means were considered according to model 6. We performed a stepwise selection of QTL (forward and backward), allowing for QTLpairwise interactions, using the Haley-Knott regression method (stepwiseqtl function). The Maximum QTL number (max.qtl) was set to five. Thresholds for incorporating new additive QTLs and epistatic interactions into the model were calculated using 100 permutations with $\alpha=0.05$ (calc.penalties function). The chosen multiple QTL model corresponded to the 
model with the largest penalized LOD score (pLOD). An ANOVA was fitted to the chosen multiple QTL model (fitqtl function). We retained QTLs in the final model when their effects were significant $(\alpha=0.05)$. Based on the same ANOVA, the percentage of variation explained by the global model and the $\mathrm{R}^{2}$ of each QTL were assessed. The fitqt function also provided the LOD value for each QTL. We finally assessed the confidence intervals of the QTL with a LOD drop of 1 (scaneone and lodint functions). QTL positions and marker names at these positions, confidence intervals, percentages of variation explained by each QTL $\left(\mathrm{R}^{2}\right)$, and favorable alleles were scored.

\section{Results}

Characterization of the crop sites

\section{Overview of the climatic data}

The growing cycles lasted for 287, 307 and 315 days for LR11, LR12 and LR13 respectively (see Supplementary Data S2). The number of days in the four periods (autumn, winter, spring and GFP) were 73/19/ 100/95 days in LR11, 87/39/66/115 days in LR12 and 97/45/55/118 days in LR13. Due to the cool and wet oceanic climate in Brittany, there were only 8, 10 and 5 days with a mean air temperature below $0{ }^{\circ} \mathrm{C}$ for LR11, LR12 and LR13 respectively. Therefore, the winter period was too short to discriminate the 3 years. However, the difference of cumulative GDD in autumn between the years (819.5 GDD/1,096.2 GDD/1,058.3 GDD in LR11, LR12 and LR13 respectively) could explain these disparities. In addition, the start of spring growth differed between the years (approximately one month difference between LR11 and the two other years) and resulted in differences in DTF, in cumulated GDD in spring and in GFP phases (Supplementary Data S2), which could also explain the variations observed.

The cumulated temperature values for the 3 years were above the minimum requirement of $2330 \mathrm{GDD}$ as defined by the CETIOM for rapeseed (Merrien and Landé 2009) with the lowest value in LR11 (2,721.4 GDD) and the highest value in LR12 (3,346 GDD). In addition, the lowest cumulated radiation in the overall cycle was in LR11 $\left(3,007.31 \mathrm{MJ} / \mathrm{m}^{2}\right.$ compared to $3,174.4^{2}$ and $3,352.91 \mathrm{MJ} / \mathrm{m}^{2}$ for LR12 and LR13 respectively). The cumulated rainfall value was the highest in LR13 during the growing cycle $(786.5 \mathrm{~mm}$ compared to 455.5 and $566 \mathrm{~mm}$ for LR11 and LR12 respectively). When the cumulated rainfall values were compared between the corresponding periods for the three years, LR12 had the lowest value during the spring period $(85.5 \mathrm{~mm}$ vs. 148 and $174.5 \mathrm{~mm}$ in LR11 and LR13 respectively) and the highest value during the GFP (297 mm vs. 104 and $188 \mathrm{~mm}$ in LR11 and LR13 respectively). The cumulated Penman evapotranspiration values over the whole cycle were relatively constant between the three years (457, 440.3, and $489.9 \mathrm{~mm}$ for LR11, LR12 and LR13 respectively). Overall from rainfall and ETP values we can conclude that water was not limiting at any time during the 3 years. In summary, LR11 had a short winter period with overall lower average daily temperatures and global radiation over the whole growing cycle. The climatic periods for LR12 and LR13 were of similar duration, with shorter spring periods and longer GFP than LR11. In addition, LR12 and LR13 were characterized by high rainfall values (especially in LR13 with a rainfall value around 1.5 fold higher than the other two locations) and higher cumulated radiation values than LR11.

\section{Characterization of $N$ constraints}

Assessment of the values of the NNI, the biomass dry matter (DM) and $\mathrm{N}$ accumulated in the aerial parts of the controls, as well as mineral $\mathrm{N}$ soil during the crop cycle gave an estimate of the $\mathrm{N}$ constraints (Fig. 1; Supplementary Data S1c, S3). At the end of autumn (date 1), no $\mathrm{N}$ deficiency was recorded, since the NNI mean values ranged between 0.91 and 1.18 and the biomass DM values ranged from 1.26 to $2.81 \mathrm{t} / \mathrm{ha}$ (Supplementary Data S3). At the end of winter (date 2), two scenarios were observed. On the one hand, plants were moderately stressed in LR11 (NNI values at date $2-0.8$ for both genotypes), probably due to $\mathrm{N}$ leaching during autumn and early vegetative regrowth. On the other hand, there was an excess of $\mathrm{N}$ in LR12 and LR13 (NNI mean values were up to 1.15 and 1.26), which was confirmed by the high amounts of $\mathrm{N}$ soil recorded on empty plots (143.4 and $73.5 \mathrm{~kg} \mathrm{~N} / \mathrm{ha}$ in LR12 and LR13 respectively, Supplementary Data S1c) and the high amount of $\mathrm{N}$ in the aerial parts of the plants (114.53 and $101.44 \mathrm{~kg} \mathrm{~N} / \mathrm{ha}$ in LR12 and LR13 compared to $50.50 \mathrm{~kg} \mathrm{~N} / \mathrm{ha}$ in 

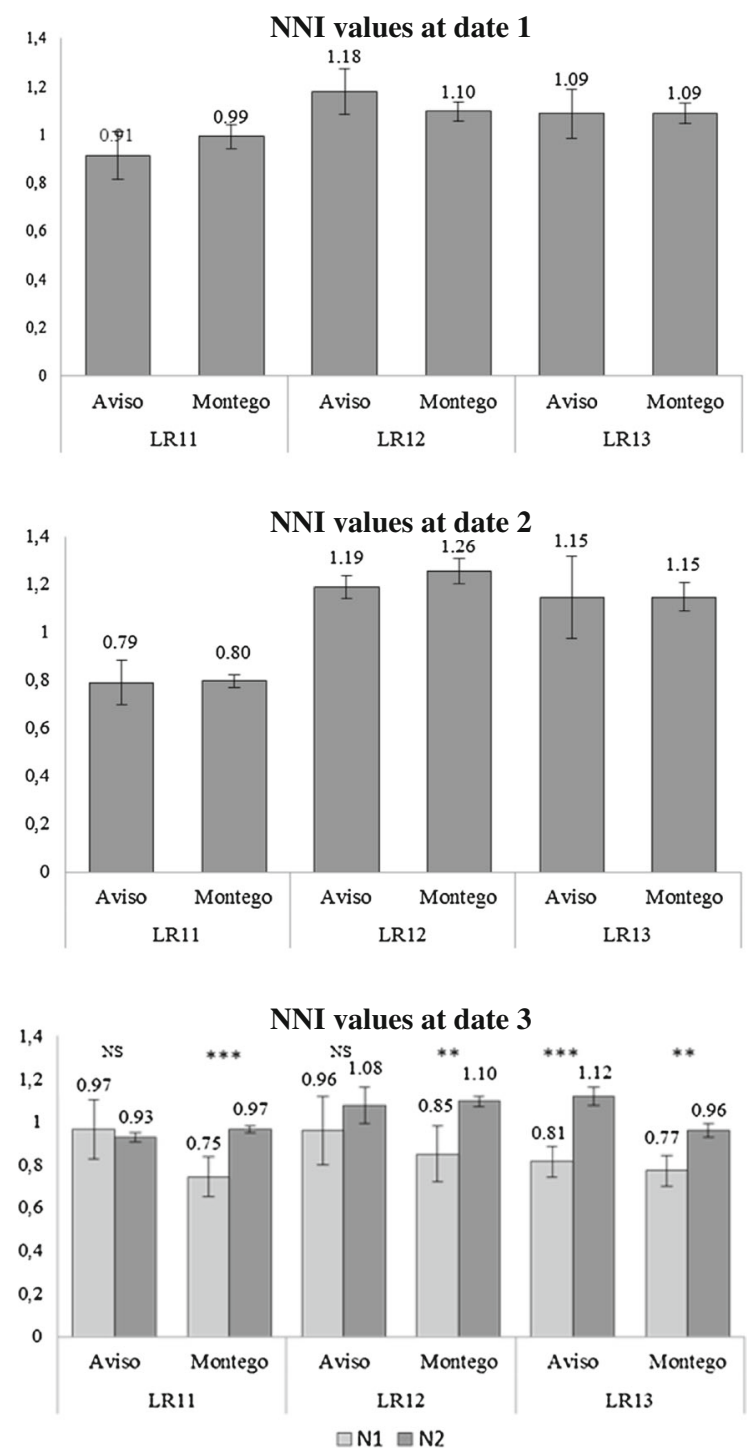

Fig. 1 NNI values measured on the Aviso and Montego genotypes at the end of autumn (date 1), the end of winter (date 2) and during the spring elongation (date 3), in LR11, LR12 and LR13. The average NNI values resulting from three (LR11) or four (LR12 and LR13) replicates are indicated on the plot along with the standard errors bars. The plants were considered stressed if the NNI values were below 0.8 . Significant differences in the NNI values between $\mathrm{N}$ conditions are indicated as follows: $* * * p$ value $<0.001, * * 0.01<p$ value $<0.001, * 0.05<p$ value, NS non-significant

LR11, Supplementary Data S3). This is probably due to a high rate of $\mathrm{N}$ mineralisation caused by the mild and humid conditions during the fall and winter seasons in LR12 and LR13.

At the flowering stage (date 3), NNI values between the two $\mathrm{N}$ conditions were significantly different for
Montego in all years and only in LR13 for Aviso ( $p$ value $<0.05$ ) (Fig. 1). When grown under the N1 condition, no $\mathrm{N}$ stress was recorded for Aviso, which always showed higher NNI values than Montego and $\mathrm{N}$ stress was observed for Montego in LR11 (NNI value at date $3=0.75$ ) and LR13 (NNI value at date $3=0.77$ ).

\section{Analyses of phenotypic data}

The phenotypic data are presented for each trait and each trial (year $\times \mathrm{N}$ combination) in Table 1. Seed yield was higher in $\mathrm{N} 2$ than in N1, except for LR12 where no significant difference was observed (Fig. 2). Positive correlations were found between seed yield, seed number $/ \mathrm{m}^{2}$, oil content and oil yield, with the highest correlation values observed between seed yield and oil yield $(\geq 0.98)$ and between seed number/ $\mathrm{m}^{2}$ and seed yield ( $\geq 0.86$ ) (Supplementary Data S4). In contrast, no significant correlation was found between seed yield and the TSW (Supplementary Data S4), suggesting that seed yield depends primarily on the seed number $/ \mathrm{m}^{2}$ and not on the weight of a grain, as illustrated in Fig. 2. A strong negative correlation was found between the oil and protein seed contents (correlation values ranged between -0.63 and -0.77 ).

The results of the mixed model (Eqs. 2 and 4) along with the heritability values $\left(\mathrm{h}^{2}\right.$, Eqs. 3,5 and 7) are shown in Tables 2, 3 and 4. A significant genotype effect was found for all the traits in every year. Similarly, a significant effect of $\mathrm{N}$ nutrition was detected for all the traits except for the seed number $/ \mathrm{m}^{2}$ in LR12. No genotype $\times \mathrm{N}$ interaction was found except for the TSW trait in LR12. Heritability values $\left(\mathrm{h}^{2}\right)$ for all the years (model 3 ) were high and ranged from 0.74 (protein yield) to 0.94 (seed oil content). The $\mathrm{h}^{2}$ values were not very different between the two $\mathrm{N}$ conditions (model 7 , Table 4). When each year was compared separately with both $\mathrm{N}$ conditions combined (model 5), the $\mathrm{h}^{2}$ values were higher for the LR12 station for every trait studied except for TSW and seed protein content. This suggests a less stressful environment in LR12 compared to the other years, leading to a lower residual variance and thus to higher $h^{2}$ values. The lowest $h^{2}$ values were recorded for the protein yield in LR13, regardless of the model used. 


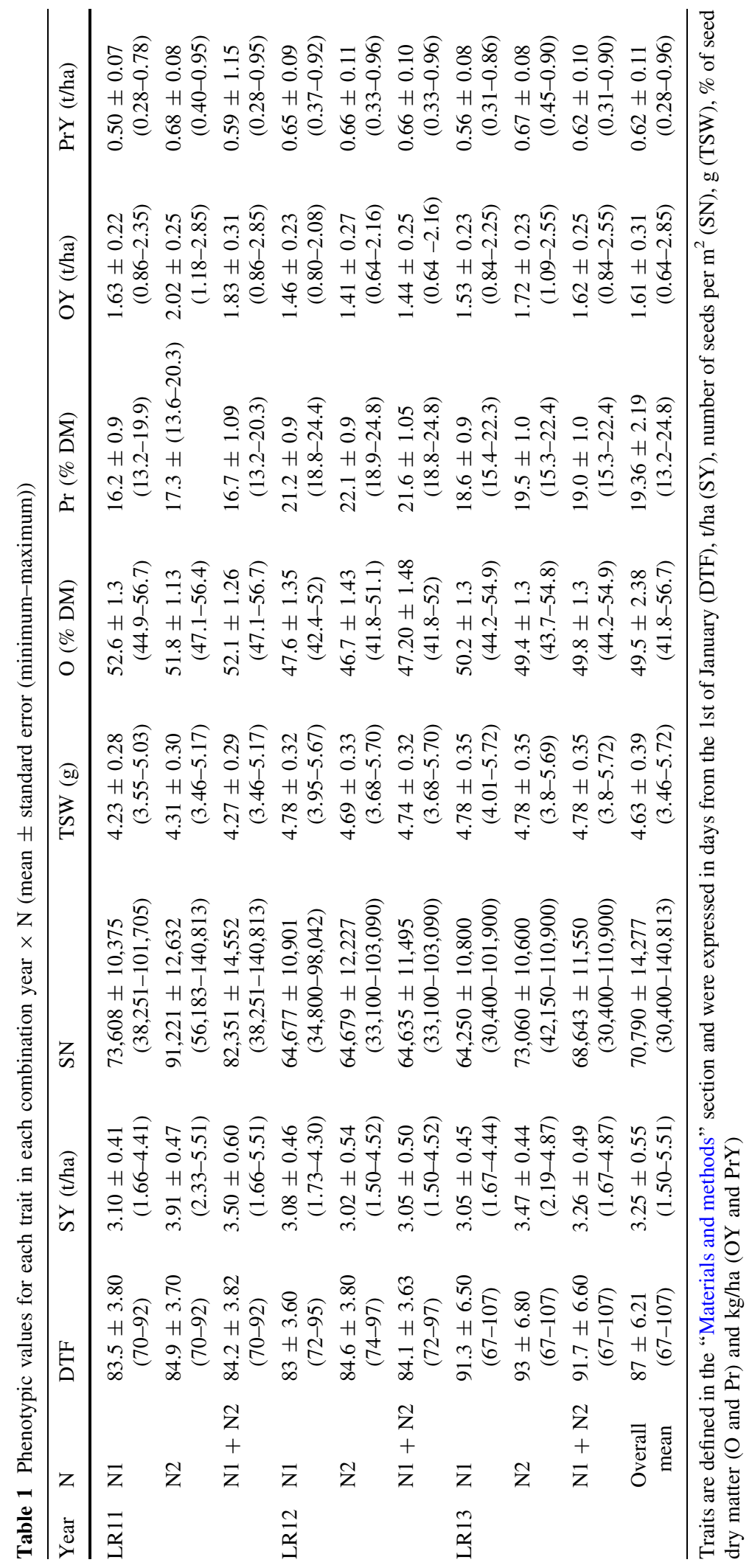




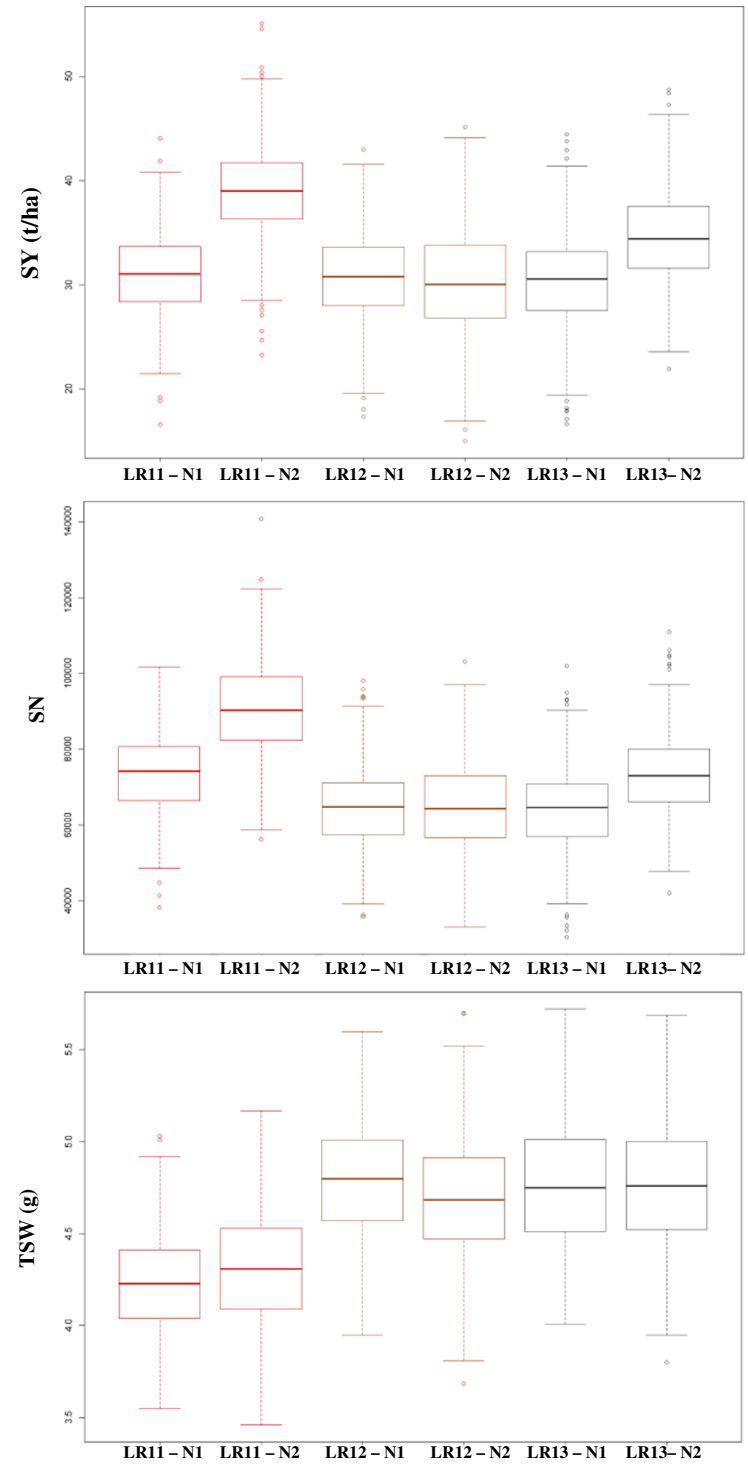

Fig. 2 Distribution of the main yield components in the AM population evaluated 3 years under two N conditions. Boxplots represent the distribution of the seed yield (SY), the thousand seed weight (TSW) and the seed number $/ \mathrm{m}^{2}$ (SN) values acquired in LR11, LR12 and LR13 trials for conditions N1 and $\mathrm{N} 2$. SY is expressed in $\mathrm{t} / \mathrm{ha}$, TSW in $\mathrm{g}$ and $\mathrm{SN}$ in number of seeds per $\mathrm{m}^{2}$

QTL analysis

\section{One hundred and four QTLs were detected all over the Brassica napus genome}

A total of 104 QTLs were detected when all traits and all environments $($ year $\times \mathrm{N}$ ) were considered. These
QTLs were distributed all over the rapeseed genome with the exception of the A8, A9 and C7 LGs, to which no QTLs localized. The LGs A5 (15 QTLs), C3 (14 QTLs), A1 (13 QTLs) and C8 (10 QTLs) carried the highest number of QTLs. The number, position, LOD score and $\mathrm{R}^{2}$ of the QTLs detected for each trait and environment $($ year $\times \mathrm{N}$ ) are summarized in Table 5 . The QTLs were mapped onto the AM genetic map (Fig. 3). Two QTLs were considered similar if their confidence intervals overlapped.

\section{Most of the QTLs were stable across $N$ conditions but not throughout the years}

Among the 104 QTLs, 28 were related to flowering time (DTF) of which 24 were highly stable among the trials and the $\mathrm{N}$ nutrition conditions, and were located on four main genomic regions on LGs A1, A2, C2 and C6 (Table 5; Fig. 3). The four remaining DTF QTLs were found on LGs A6 (identified in LR12 under N2 condition), A7 (LR11, N1 and N2 conditions), and A10 (LR11, N1 condition). The DTF QTLs on the A1, A10 and C6 LGs were putatively co-localized with other QTLs for yield components: seed number $/ \mathrm{m}^{2}$ and TSW on A1, seed number/m $\mathrm{m}^{2}$ on $\mathrm{A} 10$ and seed protein content on C6. In contrast, those located on the A2, C2, A6 and A7 LGs were DTF specific loci.

Concerning the QTLs related to yield components, a total of 76 QTLs were detected of which 36 were revealed under the $\mathrm{N} 1$ nutrition condition, 37 under the N2 condition and three were N-responsive QTLs (Table 5; Fig. 3). Some QTLs were common to the two $\mathrm{N}$ conditions and others were specific to one $\mathrm{N}$ condition only (Fig. 4a). For instance, in LR11, 29 QTLs were found in total with 12 N1 specific QTLs, nine N2 specific QTLs and four QTLs found in both N nutrition conditions; in LR12, 22 QTLs were found in total with three N1 specific QTLs, three N2 specific QTLs and eight found in both $\mathrm{N}$ nutrition conditions; in LR13, 22 QTLs were found in total, with two N1 specific QTLs, six N2 specific QTLs and seven QTLs found in both $\mathrm{N}$ conditions. Very few QTLs were common to at least two out of the 3 years (Fig. $4 \mathrm{~b}$ ). Thus, when considering the N1 condition alone, no QTLs were common to the 3 years, four QTLs were identified in 2 years and 28 QTLs were specific to 1 year. Considering the $\mathrm{N} 2$ condition only, none of the QTLs were common to the 3 years, five were found in 2 years and 27 were specific to 1 year. 
Table 2 Results of the mixed linear model 2: $P_{i j k l}=\mu+G_{i}+$ $N_{j}+Y_{l}+G_{i} \times N_{j}+Y_{l}\left(R_{k}\right)+G_{i} \times Y_{l}+e_{i j k l m} ;$ mean square (MS) values along with significance of the genotype $(\mathrm{G})$, the year $(\mathrm{Y})$, the nitrogen level $(\mathrm{N})$, the genotype $\times$ nitrogen interaction $(\mathrm{G} \times \mathrm{N})$ and the genotype $\times$ year $(\mathrm{G} \times \mathrm{Y})$ effects on every trait studied is indicated

\begin{tabular}{|c|c|c|c|c|c|c|c|c|c|c|}
\hline & \multicolumn{2}{|l|}{ G } & \multicolumn{2}{|l|}{$\mathrm{Y}$} & \multicolumn{2}{|l|}{$\mathrm{N}$} & \multicolumn{2}{|l|}{$\mathrm{G} \times \mathrm{N}$} & \multicolumn{2}{|l|}{$G \times Y$} \\
\hline & MS & $p$ value & MS & $p$ value & MS & $p$ value & MS & $p$ value & MS & $p$ value \\
\hline SY & 160 & $* * *$ & 3,999 & $* *$ & 189.5 & $* * *$ & 40 & NS & 12.7 & $* * *$ \\
\hline $\mathrm{SN}$ & $9.6 \times 10^{8}$ & $* * *$ & $1.81 \times 10^{9}$ & $* *$ & $3.96 \times 10^{10}$ & $* * *$ & $7.73 \times .10^{7}$ & NS & $5.34 \times 10^{8}$ & $* * *$ \\
\hline TSW & & NA & & NA & & NA & & NA & & NA \\
\hline $\mathrm{O}$ & 19.3 & $* * *$ & 61.8 & $* * *$ & 490.3 & $* * *$ & 0.62 & $* *$ & 1.98 & $* * *$ \\
\hline $\operatorname{Pr}$ & 7.5 & $* * *$ & 69.6 & $* * *$ & 677.4 & $* * *$ & 0.46 & $* *$ & 1.12 & $* * *$ \\
\hline OY & $4.7 \times 10^{5}$ & $* * *$ & $1.0 \times 10^{6}$ & $* *$ & $1.5 \times 10^{8}$ & $* * *$ & $3.1 \times 10^{4}$ & NS & $1.1 \times 10^{5}$ & $* * *$ \\
\hline $\operatorname{PrY}$ & $4.0 \times 10^{4}$ & $* * *$ & $6.9 \times 10^{4}$ & $* *$ & $5.7 \times 10^{6}$ & $* * *$ & $5.6 \times 10^{3}$ & NS & $1.4 \times 10^{4}$ & $* * *$ \\
\hline
\end{tabular}

$N S$ non-significant, $N A$ not available

$* * * p$ value $<0.001, * * 0.01<p$ value $<0.001, * 0.05<p$ value

Table 3 Results of the mixed linear model 4: $P_{i j k l}=\mu+G_{i}+N_{j}+R_{k}+G_{i} \times N_{l}+e_{i j k l}$; significance of the genotype (G), nitrogen level $(\mathrm{N})$ and the genotype $\times$ nitrogen interaction $(\mathrm{G} \times \mathrm{N})$ effect is assessed for each year (LR11, LR12 and LR13) separately

\begin{tabular}{|c|c|c|c|c|c|c|c|}
\hline & & \multicolumn{2}{|l|}{ G } & \multicolumn{2}{|l|}{$\mathrm{N}$} & \multicolumn{2}{|l|}{$\mathrm{G} \times \mathrm{N}$} \\
\hline & & MS & $p$ value & MS & $p$ value & MS & $p$ value \\
\hline \multirow[t]{3}{*}{ SY } & LR11 & 51.7 & $* * *$ & 7,401 & $* *$ & 9.4 & NS \\
\hline & LR12 & 119.8 & $* * *$ & 74.7 & $* *$ & 11.1 & NS \\
\hline & LR13 & 66.8 & $* * *$ & 4463 & $* * *$ & 10.1 & NS \\
\hline \multirow[t]{3}{*}{$\mathrm{SN}$} & LR11 & $3.58 \times 10^{8}$ & $* * *$ & $1.28 \times 10^{10}$ & $* *$ & $5.75 \times 10^{7}$ & NS \\
\hline & LR12 & $6.52 \times 10^{8}$ & $* * *$ & $6.45 \times 10^{5}$ & NS & $6.31 \times 10^{7}$ & NS \\
\hline & LR13 & $4.65 \times 10^{8}$ & $* * *$ & $1.94 \times 10^{10}$ & $* * *$ & $5.25 \times 10^{7}$ & NS \\
\hline \multirow[t]{3}{*}{ TSW } & LR11 & 0.41 & $* * *$ & 0.17 & $* *$ & 2.1 & NS \\
\hline & LR12 & 0.49 & $* * *$ & 2.13 & $* * *$ & 0.07 & $* * *$ \\
\hline & LR13 & NA & NA & NA & NA & NA & NA \\
\hline \multirow[t]{3}{*}{$\mathrm{O}$} & LR11 & 5.2 & $* * *$ & 35.2 & $*$ & 0.6 & NS \\
\hline & LR12 & 9.54 & $* * *$ & 275.4 & $* * *$ & 0.59 & NS \\
\hline & LR13 & 9.76 & $* * *$ & 138.8 & $* * *$ & 0.49 & NS \\
\hline \multirow[t]{3}{*}{$\operatorname{Pr}$} & LR11 & 1.9 & $* * *$ & 21 & $*$ & 0.5 & NS \\
\hline & LR12 & 3.52 & $* * *$ & 260.1 & $* * *$ & 0.37 & NS \\
\hline & LR13 & 1.17 & $* * *$ & 195 & $* * *$ & 0.35 & NS \\
\hline \multirow[t]{3}{*}{ OY } & LR11 & $1.58 \times 10^{5}$ & $* * *$ & $1.22 \times 10^{7}$ & $* *$ & $2.44 \times 10^{4}$ & NS \\
\hline & LR12 & $3.13 \times 10^{5}$ & $* * *$ & $7.87 \times 10^{5}$ & $* * *$ & $2.67 \times 10^{4}$ & NS \\
\hline & LR13 & $2.1 \times 10^{5}$ & $* * *$ & $8.6 \times 10^{6}$ & $* * *$ & $2.6 \times 10^{4}$ & NS \\
\hline \multirow[t]{3}{*}{ PrY } & LR11 & $1.29 \times 10^{4}$ & $* * *$ & $5.36 \times 10^{6}$ & $* * *$ & 3,868 & NS \\
\hline & LR12 & $4.64 \times 10^{4}$ & $* * *$ & $8.32 \times 10^{4}$ & $* * *$ & 5,460 & NS \\
\hline & LR13 & $1.7 \times 10^{4}$ & $* * *$ & $2.9 \times 10^{6}$ & $* * *$ & 4,103 & NS \\
\hline
\end{tabular}

$M S$ mean square, $N S$ non-significant, $N A$ not available

$* * * p$ value $<0.001, * * 0.01<p$ value $<0.001, * 0.05<p$ value 
Table 4 Heritability $\left(h^{2}\right)$ values are shown for each trait according to the models 3,5 , and 7

\begin{tabular}{|c|c|c|c|c|c|}
\hline Trait & Site & $\begin{array}{l}\mathrm{h}^{2} \text { model } \\
7-\mathrm{N} 1^{\mathrm{a}}\end{array}$ & $\begin{array}{l}\mathrm{h}^{2} \text { model } \\
7-\mathrm{N} 2^{\mathrm{a}}\end{array}$ & $\begin{array}{l}\mathrm{h}^{2} \\
\text { model } \\
5^{\mathrm{b}}\end{array}$ & $\begin{array}{l}\mathrm{h}^{2} \\
\text { model } \\
3^{\mathrm{c}}\end{array}$ \\
\hline \multirow[t]{3}{*}{ SY } & LR11 & 0.72 & 0.64 & 0.8 & \multirow[t]{3}{*}{0.83} \\
\hline & LR12 & 0.89 & 0.84 & 0.91 & \\
\hline & LR13 & 0.64 & 0.72 & 0.82 & \\
\hline \multirow[t]{3}{*}{ SN } & LR11 & 0.77 & 0.7 & 0.84 & \multirow[t]{3}{*}{0.87} \\
\hline & LR12 & 0.87 & 0.85 & 0.89 & \\
\hline & LR13 & 0.73 & 0.8 & 0.87 & \\
\hline \multirow[t]{3}{*}{ TSW } & LR11 & 0.94 & 0.95 & 0.95 & \multirow[t]{3}{*}{ NA } \\
\hline & LR12 & 0.82 & 0.86 & 0.87 & \\
\hline & LR13 & 0.95 & 0.96 & NA & \\
\hline \multirow[t]{3}{*}{$\mathrm{O}$} & LR11 & 0.73 & 0.87 & 0.89 & \multirow[t]{3}{*}{0.94} \\
\hline & LR12 & 0.93 & 0.9 & 0.93 & \\
\hline & LR13 & 0.9 & 0.88 & 0.95 & \\
\hline \multirow[t]{3}{*}{$\operatorname{Pr}$} & LR11 & 0.55 & 0.68 & 0.76 & \multirow[t]{3}{*}{0.92} \\
\hline & LR12 & 0.87 & 0.85 & 0.89 & \\
\hline & LR13 & 0.84 & 0.79 & 0.92 & \\
\hline \multirow[t]{3}{*}{ OY } & LR11 & 0.83 & 0.67 & 0.86 & \multirow[t]{3}{*}{0.86} \\
\hline & LR12 & 0.9 & 0.84 & 0.91 & \\
\hline & LR13 & 0.7 & 0.96 & 0.86 & \\
\hline \multirow[t]{3}{*}{ PrY } & LR11 & 0.88 & 0.95 & 0.69 & \multirow[t]{3}{*}{0.74} \\
\hline & LR12 & 0.87 & 0.84 & 0.87 & \\
\hline & LR13 & 0.51 & 0.62 & 0.74 & \\
\hline
\end{tabular}

$N A$ not available

${ }^{a} h^{2}$ values assessed according to the model 7: $h^{2}=\frac{\sigma_{G}^{2}}{\sigma_{G}^{2}+\frac{\sigma_{e}^{2}}{r}}$ for each year and each $\mathrm{N}$ condition

${ }^{\mathrm{b}} \mathrm{h}^{2}$ values assessed according to the model 5: $h^{2}=\frac{\sigma_{G}^{2}}{\sigma_{G}^{2}+\frac{\sigma_{G \times N}^{2}}{n}+\frac{\sigma_{e}^{2}}{n \times r}}$ for each year and all $\mathrm{N}$ conditions

${ }^{\mathrm{c}} \mathrm{h}^{2}$ values assessed according to the model $3: h^{2}=$ $\frac{\sigma_{G}^{2}}{\sigma_{G}^{2}+\frac{\sigma_{G \times N}^{2}}{n}+\frac{\sigma_{G \times Y}^{2}}{y}+\frac{\sigma_{e}^{2}}{y \times n \times r}}$ for all years and all $\mathrm{N}$ conditions

\section{Eleven main genomic regions are critical} for the elaboration of oil yield

To obtain an overview of the key genomic regions involved in yield within the AM population, we tried to group the 76 QTLs controlling yield components using the following criterion: a critical region must carry overlapping QTLs for one or several traits that were stable in at least two environments $(\mathrm{N}$ and/or site). The confidence intervals of the critical genomic regions were defined as the overlapping of constitutive QTLs confidence intervals. As a result, we identified 11 critical genomic regions that were located on seven LGs as shown in Fig. 3 and Supplementary Data S5.

Seven of these 11 regions carried QTLs for only one trait of which four were for TSW (Region $(R)-A 4, R$ $A 10-a, R-C 1-b$ and $R-C 3-c)$, two for oil content ( $R-C l-$ $a$ and $R-C 3-b)$ and the last one for seed number $/ \mathrm{m}^{2}(R-$ $A 10-b$ ). In addition, four of the seven mono-trait regions were specific to 1 year $(R-A 10-a, R-A 10-b, R$ $C 1-b$ and $R-C 3-b$ specific to LR13, LR11, LR13 and LR13 respectively). The four remaining regions (namely $R-A 1, R-A 5, R-C 3-a$ and $R-C 8$ ) carried QTLs for multiple traits and were designated as yield-related regions. Three of these four regions were specific to one site $(R-A 1, R-C 3-a$ and $R-C 8$ specific to LR13, LR1 1 and LR12 respectively) whereas the last one ( $R$ $A 5)$ carried QTLs found in 2 years (LR11 and LR12). The most promising region appears to be $R-A 5$ (10-64 cM) to which 12 stable QTLs for seed yield, oil yield, protein yield and seed number $/ \mathrm{m}^{2}$ were localized (QTLs found in N1, N2, LR11 and LR12).

\section{Epistatic interactions}

Only one epistatic interaction was detected in the N1 condition of the LR11 trial with an interaction between QTLs of TSW found on the C3 and C9 LGs. The percentage of variation explained by this interaction was $6.48 \%$ where the main effects were 20.9 and $18.66 \%$ for the C3 and C9 TSW QTLs, respectively.

\section{Discussion}

The aim of the present study was to determine the genetic regions involved in grain yield and yield components in OSR grown under contrasting $\mathrm{N}$ regimes over 3 years of trial. The high number of QTL detected in our study highlights the complexity of the genetic control of yield in OSR. Eleven critical genomic regions carrying stable QTLs across years and/or $\mathrm{N}$ conditions were detected and are promising potential candidates for OSR breeding programs. A particularly dense region on the A5 LG (R-A5) grouped 12 QTLs related to yield components. The potential for using these regions in breeding strategies is discussed. 


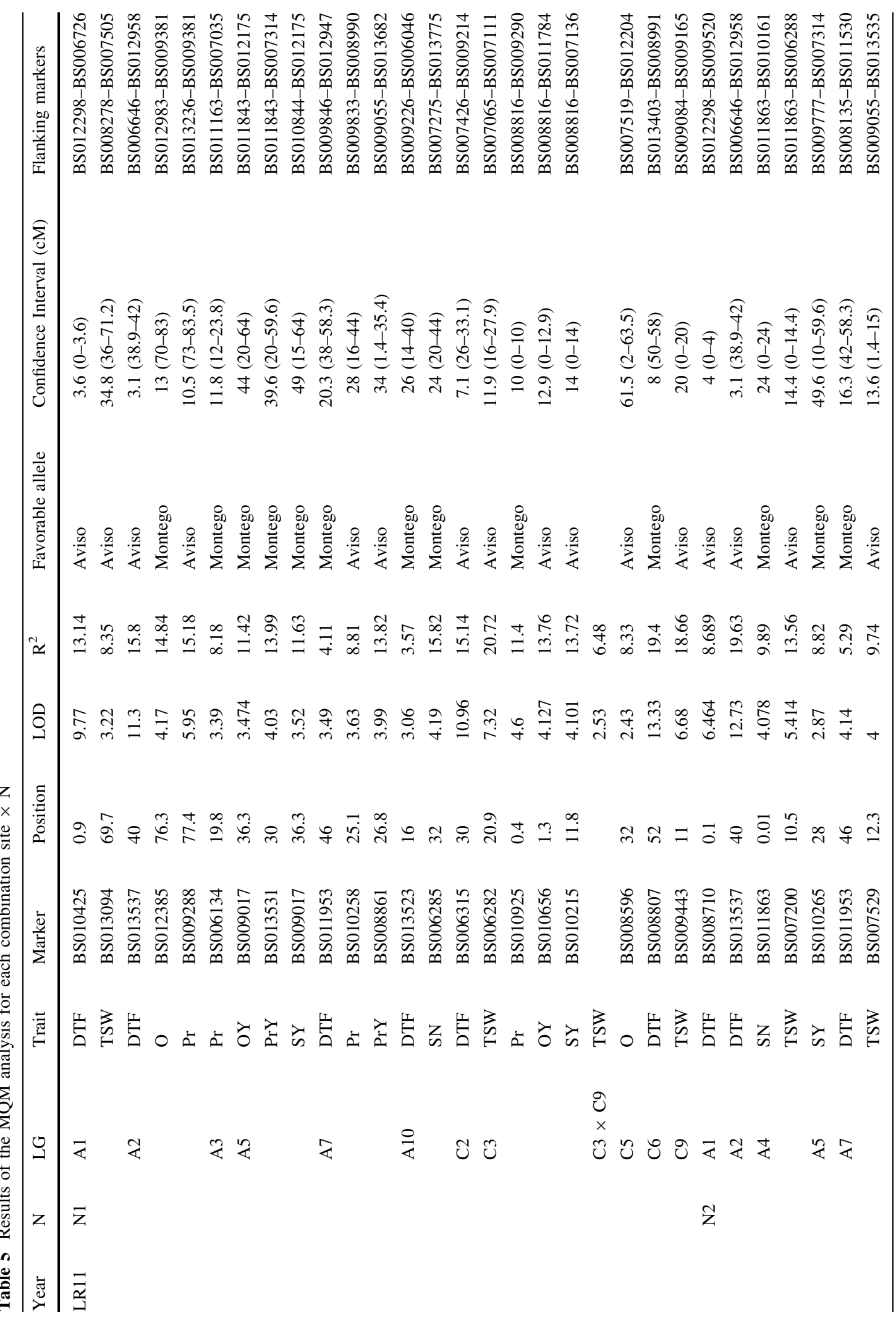




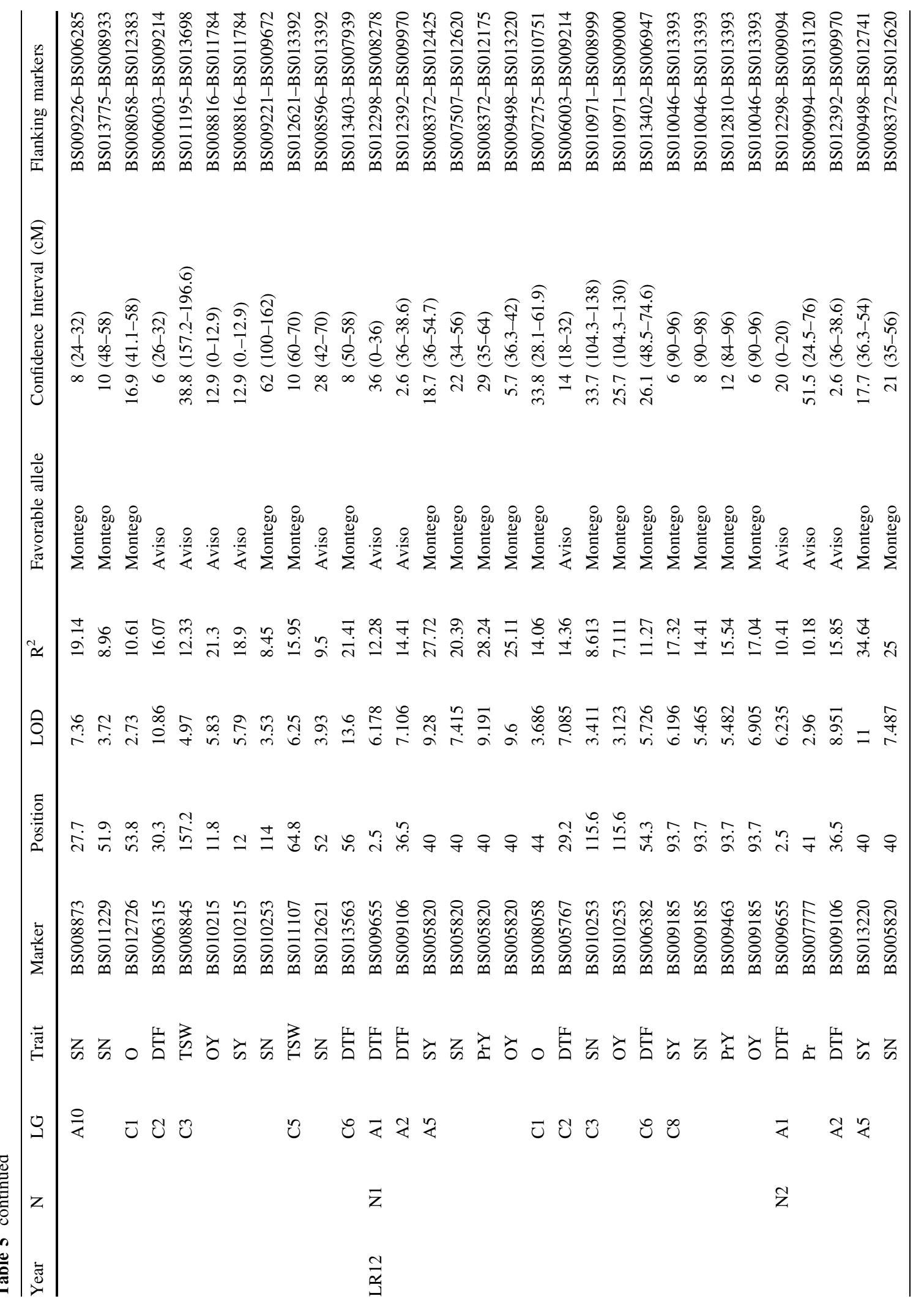




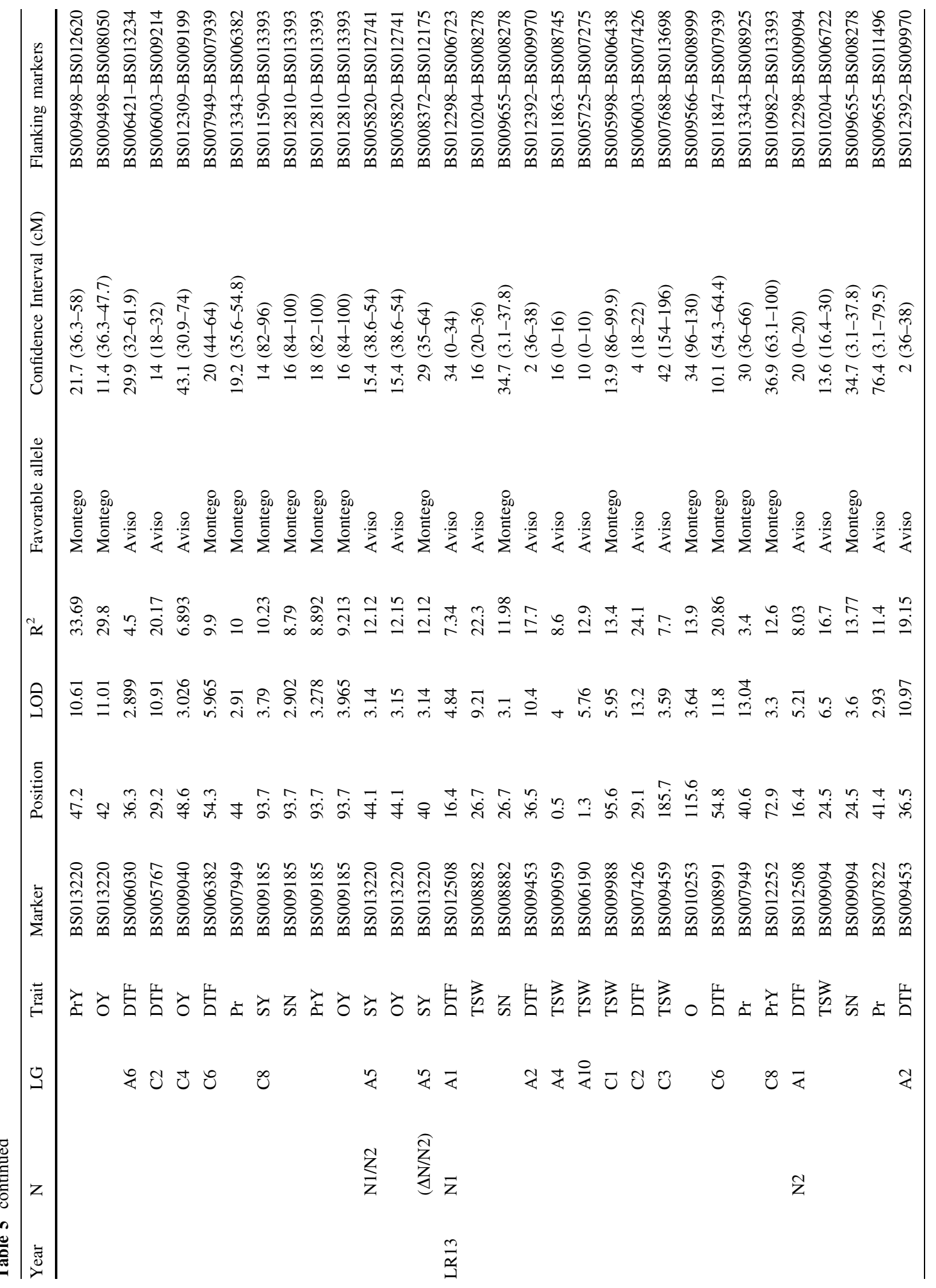




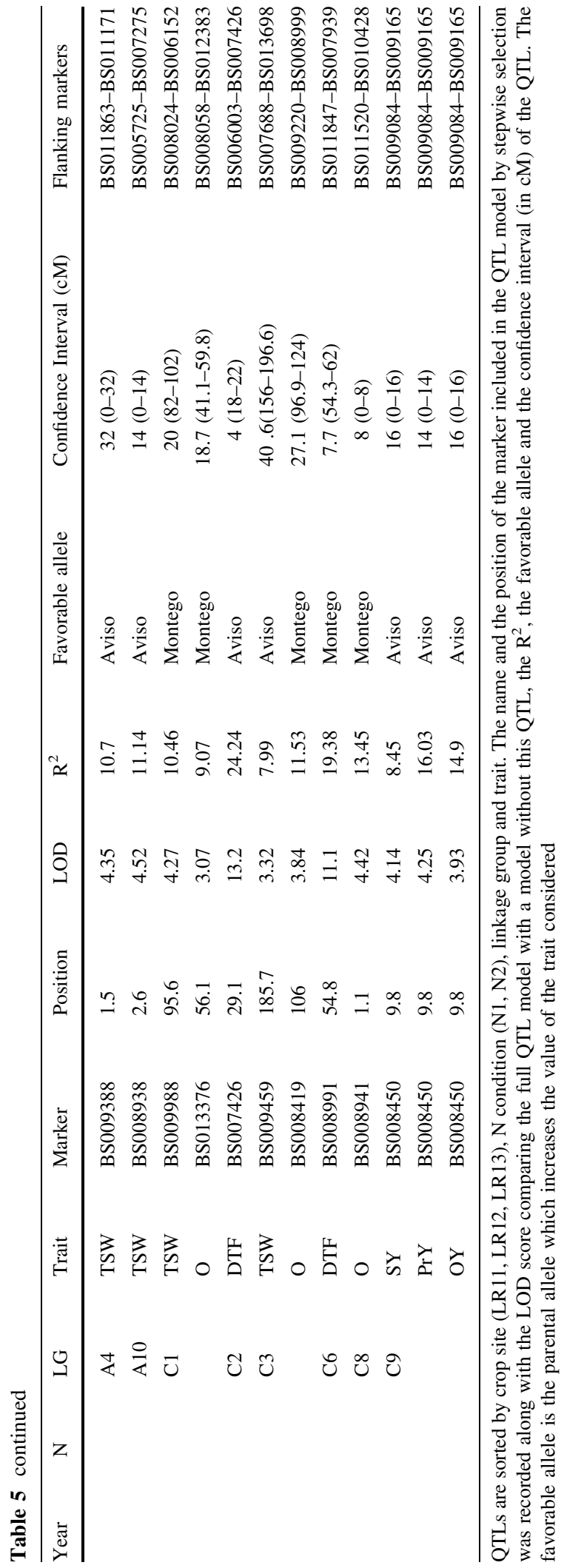

Power of QTL detection in the AM population

Flowering time is a major developmental trait known to interact with yield components (Diepenbrock 2000). We investigated DTF QTLs and found 28 loci involved in the genetic control of flowering time. Most of the DTF QTLs defined four genomic regions located on A1, A2, C2 and C6 that were stable across the environments $($ year $\times \mathrm{N}$ ). The DTF region on $\mathrm{C} 2$ corresponded to the FLC4 gene (data not shown) previously cloned in B. napus (Tadege et al. 2001). In addition, DTF QTLs located on A1, A2 and C6 were also reported previously in different genetic backgrounds (Delourme et al. 2006). The DTF region on A1 showed a possible co-localization with the yieldrelated genomic region $R-A l$.

Seventy-six yield-related QTLs were identified which explained from 3.4 (QTL for protein content on C6) to $34.6 \%$ (seed yield QTL on A5) of the total variation of the traits studied. Their confidence intervals ranged from 5.7 (oil yield QTL on A5) to $76.4 \mathrm{cM}$ (QTL for protein content on A5). This can be explained by the relatively small size of the AM population (112 individuals) which results in a decreased power of QTL detection (low number of detected QTLs, overestimation of the QTL effects as well as the size of the confidence intervals) (Bernardo 2008). However, due to the experimental design which included two $\mathrm{N}$ conditions and several (three to four) replicates, a higher number of individuals would have been very difficult to manage and one hundred individuals should adequately balance the precision of QTL detection and the experimental constraints (Vales et al. 2005).

More than $20 \%$ of the SNPs were in segregation distortion at the whole genome scale, which is commonly observed in DH populations compared to other kinds of segregating populations (Zhang et al. 2010). The impact of segregation distortions on QTL mapping have been reported (Liu et al. 2010) but appeared to be minimized with large populations and when the distance between the distorted markers and the QTLs is over $40 \mathrm{cM}$ (Zhang et al. 2010). In our case, a total of 16 yield-related QTLs should be considered with care due to a possible effect of genetic distortion within their vicinities. These QTLs were located on A2, A3, A7 and C4 and in the two regions $R-C 1-a$ and $R-C 3-a$. However, by deleting distorted markers from the analysis we would have run the risk 


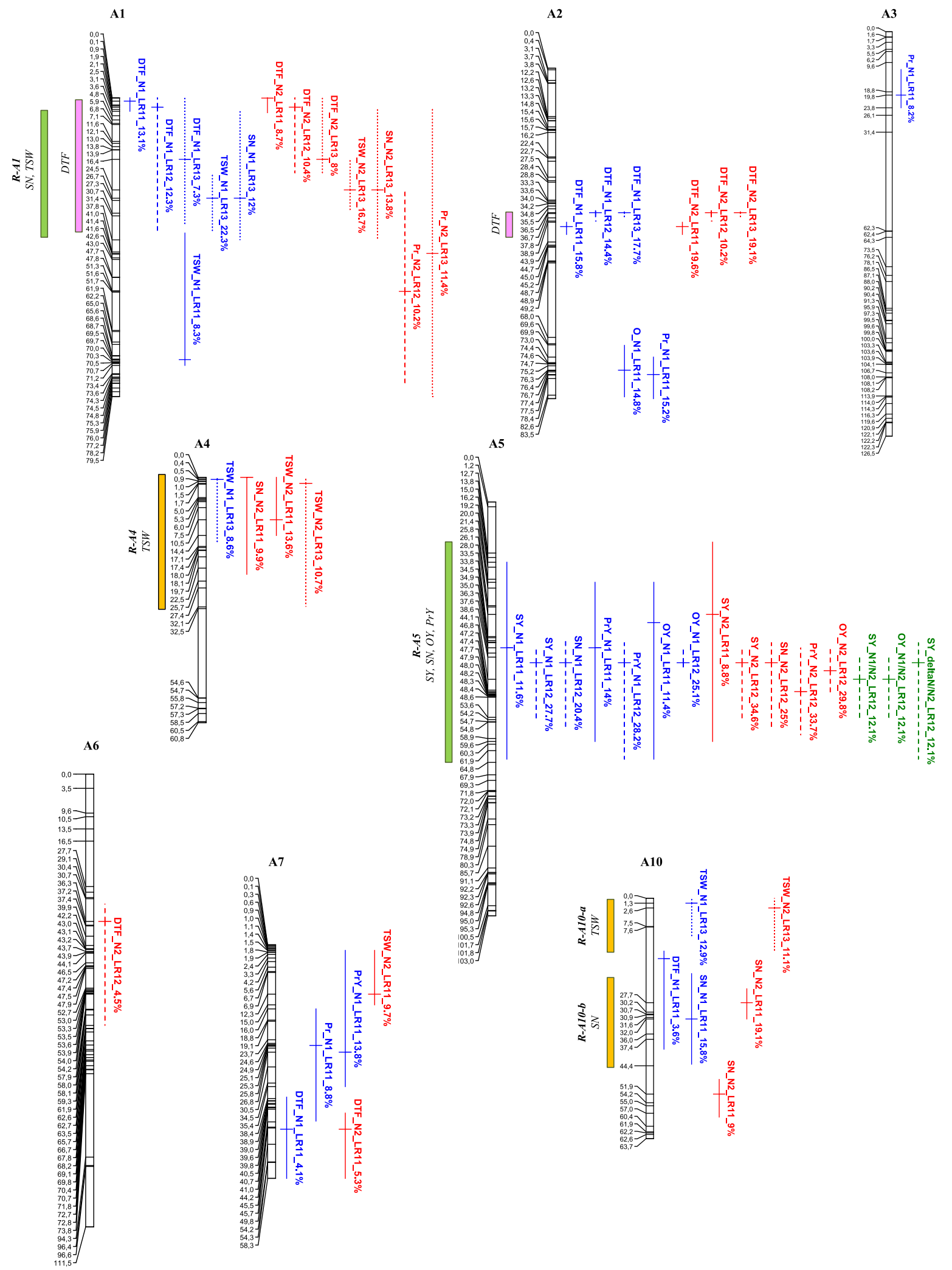


4 Fig. 3 Schematic representation of the 104 QTLs identified in this study on the "Aviso $\times$ Montego" genetic map. Each QTL is labeled with the name of the corresponding trait (DTF, SY, SN, TSW, O, Pr, OY, PrY), the year (LR11, LR12, LR13), the N condition $(\mathrm{N} 1, \mathrm{~N} 2)$ and the $\mathrm{R}^{2}$ value given in $\%$. The N1-QTLs are written in blue, the N2-QTLs in red and the N-responsive QTLs in green. The QTLs found in LR11 are represented with plain lines, the QTLs found in LR12 by dashed lines and the QTLs found in LR13 by dotted lines. The DTF regions are indicated by pink bars on the left side of the LGs. The eleven critical regions involved in yield and yield components are indicated by: (1) green bars for regions containing QTLs for multiple traits and (2) orange bars for regions containing QTLs for one trait. Refer to Table 5 for exact positions of the QTLs and the names of the markers at these positions, and to Supplementary Data S5 for the description of the eleven critical regions. (Color figure online)

of missing QTLs (Liu et al. 2010). The 60 other yieldrelated QTLs were far from distorted markers $(>40 \mathrm{cM})$ and can therefore be considered reliable.

Yield-related QTLs were gathered on eleven critical genomic regions with a particular dense seed yield area on the A5 linkage group

We identified eleven critical genomic regions encompassing seven LGs where yield-related QTLs were stable across $\mathrm{N}$ conditions and/or years of trial. Seven regions corresponded to mono-traits and the four others were multi-traits. Except for the $R-A 1$, the multi-trait regions carried QTLs for correlated traits. Indeed, QTLs of seed yield and seed number $/ \mathrm{m}^{2}$ were often co-localized. This was particularly obvious for the $R$ - $A 5$ region where 12 QTLs for seed yield, seed number $/ \mathrm{m}^{2}$, protein yield and oil yield co-localized. Previous studies also reported the co-localization of QTLs controlling yield and yield components in $B$. napus (Ding et al. 2012) or in other species such as in rice (Wei et al. 2012). This raises the question of whether these regions result from the genetic linkage of several independent QTLs or whether they carry master regulators with pleiotropic effects as suggested by Shi et al. (2009). Considering the complexity of seed yield, it appears more than likely that many genes contribute directly or indirectly to this trait (Slafer 2003) and that both the suggested mechanisms play a significant role. In addition, in our study several QTLs for traits that were negatively correlated also colocalized. For instance, QTLs controlling seed protein content or seed oil content co-localized on A2 although the two corresponding traits were strongly negatively correlated (Supplementary Data S4), thus confirming the literature (Jeuffroy et al. 2006). Here, the two QTLs displayed opposite allelic effects. This demonstrates the complexity of combining favorable alleles for two competitive traits. Focusing on QTLs that may be inherited independently may be a necessary strategy for obtaining high seed oil and protein content. Thus, QTLs of protein content on the A1, A3, A7 and C3 LGs and QTLs of seed oil content on the C1, C3 and C8 LGs could be considered for improving both traits simultaneously, after validation in other environments.

QTLs for yield components on A4 (QTL for TSW, Ding et al. 2012), A8 (QTLs for seed yield, TSW and seed number/area; Shi et al. 2009) and C3 (Zhao et al. 2012) were previously reported in rapeseed, and appear to correspond to the regions $R-A 4, R-A 8$ and $R-C 3-b$ described in the present study. In addition, several studies already reported the presence of QTLs for seed yield related traits on the A5 LG (Ding et al. 2012; Fan et al. 2010; Shi et al. 2009), which supports the hypothesis that this is a critical region for plant breeding purposes. Our study showed the importance of $R-A 5$ effects on yield related traits $\left(8.82<\mathrm{R}^{2}<34.64 \%\right)$ and its stability with time and environment, which, to our knowledge, had not yet been demonstrated. However, this region needs to be further characterized using additional genetic backgrounds before being considered as a serious candidate for plant breeding. Association mapping would be a relevant tool to both confirms $R-A 5$ in a wide set of genotypes and to determine more precise data on its position and confidence interval.

QTLs were stable across $\mathrm{N}$ conditions but differed between trial years

Several genetic analyses conducted under abiotic constraints, including $\mathrm{N}$ stress, have been published for crops such as wheat (Campbell et al. 2003; Laperche et al. 2007) or rapeseed (Miro 2010) and reported interactions between QTLs and abiotic stress. However, (Gül 2002; Gül et al. 2003) showed that only few QTLs had a significant interaction with $\mathrm{N}$ nutrition regime in rapeseed, which was confirmed by our results. Indeed, in the present study, the QTLs were relatively stable between the $\mathrm{N}$ conditions and very few $\mathrm{G} \times \mathrm{N}$ and $\mathrm{QTL} \times \mathrm{N}$ interactions were significant. Only 17-18 QTLs were specific to one or 

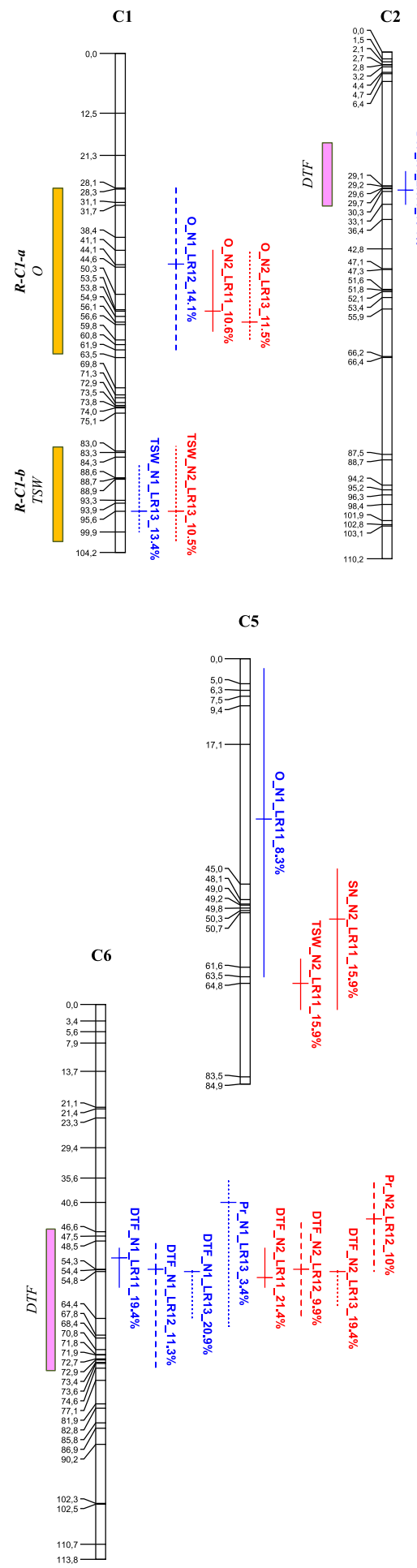
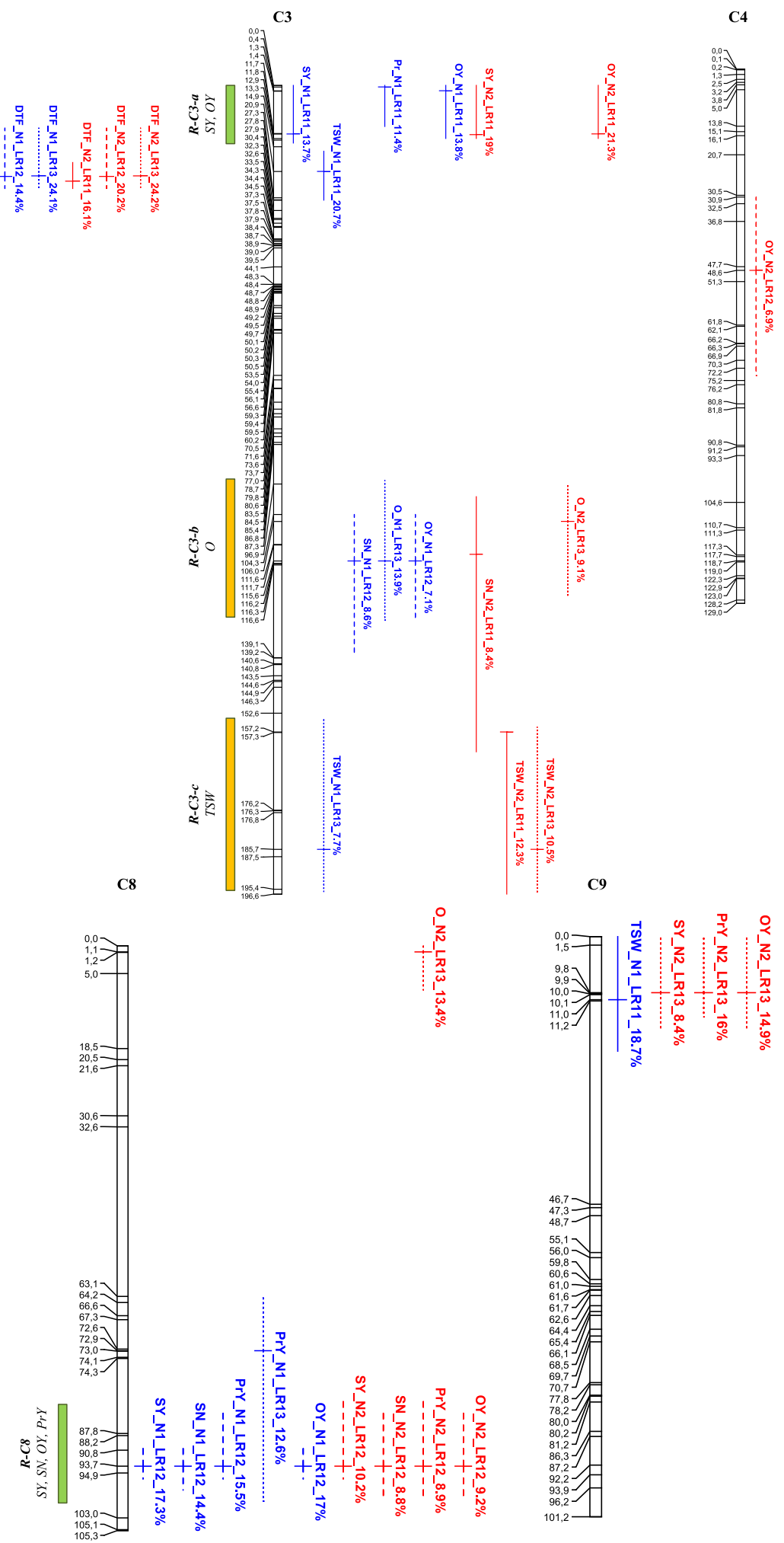

Fig. 3 continued 

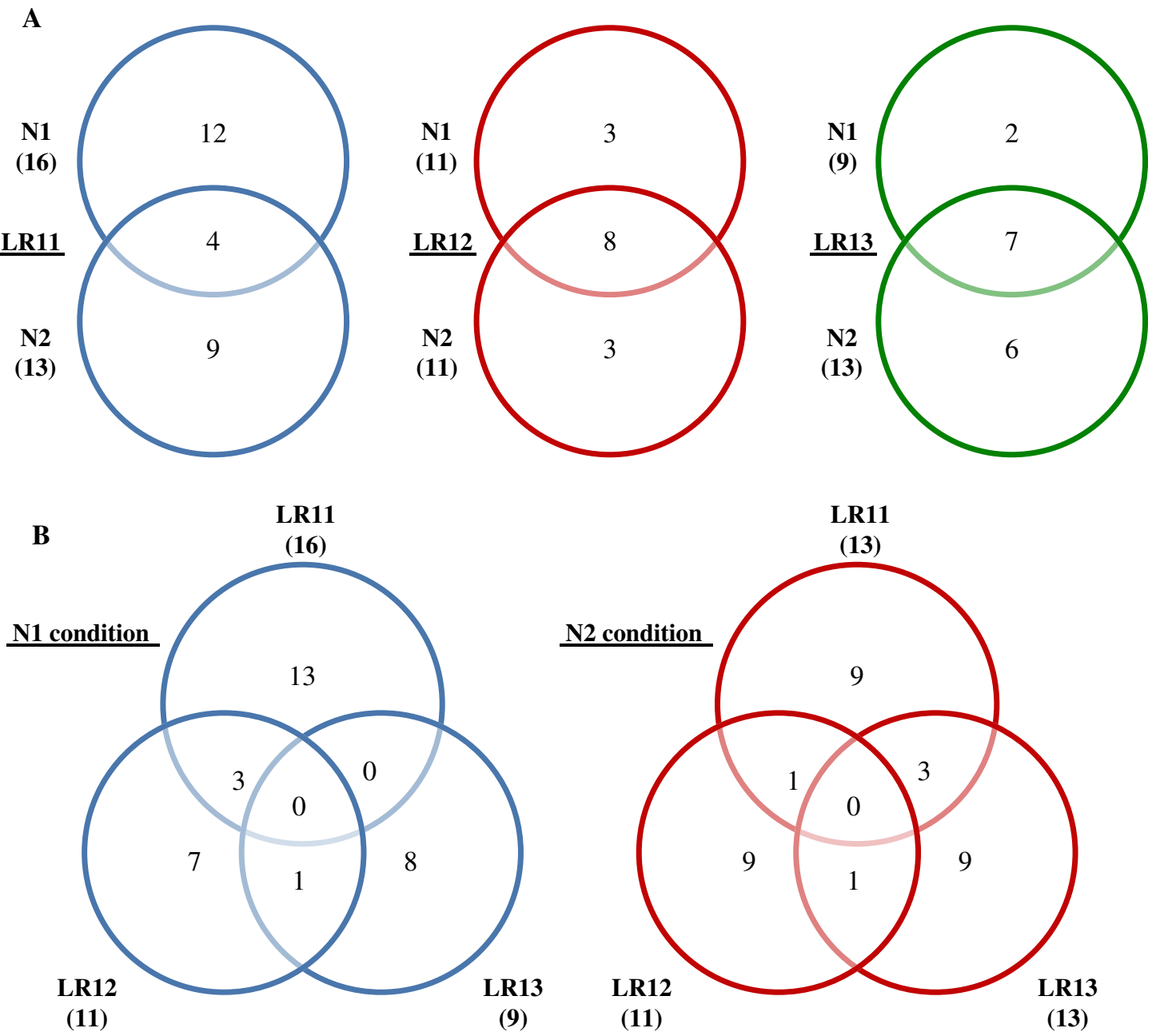

Fig. 4 Number of QTLs detected for all traits. a Number of QTLs found in each $\mathrm{N}$ condition for each year. The numbers at the intersections of the circles correspond to the QTLs common

the other $\mathrm{N}$ condition. In LR12 and LR13, many QTLs were found to be consistent between $\mathrm{N}$ conditions with only six and eight QTLs specific to one $\mathrm{N}$ condition in LR12 and LR13 respectively and only three QTLs which reacted to a change in $\mathrm{N}$ condition $((\mathrm{N} 1 / \mathrm{N} 2)$ and $(\Delta \mathrm{N} / \mathrm{N} 2))$ were found in LR12 site on the A5 LG. This could be due to the limited $\mathrm{N}$ stress induced in the $\mathrm{N} 1$ condition, especially in LR12 and LR13. Another explanation could lie in the ability of $B$. napus to compensate for a developmental phase that was not optimal (for example, poor $\mathrm{N}$ remobilization in the seeds during the GFP) by improving another step of development (for instance, an increase in the number of ramifications leading to an increased number of seeds per area). Furthermore, under low N, rapeseed

to the two $\mathrm{N}$ conditions. b Number of QTLs found in each year for each $\mathrm{N}$ condition. The numbers at the intersections of the circles correspond to the QTLs common to 2 or 3 years of trial

seed yield is positively correlated with the NUpE, whereas it is more correlated with the NUtE under a high N (Berry et al. 2010; Schulte auf'm Erley et al. 2011). This suggests that there are physiological differences between genotypes with contrasted NUE [root system, amount of $\mathrm{N}$ accumulated in the stems, for instance (Berry et al. 2010)] that were not studied here. Thus, refining the analysis of seed yield by studying physiological traits throughout the cycle would allow pinpointing the exact steps when OSR yield components development strategy is modified under $\mathrm{N}$ limitation. Although $\mathrm{N}$ stress was not pronounced in our experiments (NNI values close to 0.8 and small differences in seed yield between the two $\mathrm{N}$ conditions), the NNI values at date three in N1 
were significantly lower than in $\mathrm{N} 2$ for Montego in all years and for Aviso in LR13, suggesting that the plants showed a difference in $\mathrm{N}$ nutrition between the two $\mathrm{N}$ conditions. To explore this diversity of $\mathrm{N}$ nutrition, the analysis could focus on the response of rapeseed to a gradient of NNI by examining the trait values as the difference in NNI values between the two $\mathrm{N}$ conditions instead of using the values in $\mathrm{N} 1$ and $\mathrm{N} 2$ per se. Nevertheless, 17 QTLs were found to be specific to the N1 nutrition condition (on LGs A2, A3, A7, C3, C5, $\mathrm{C} 8$ and $\mathrm{C} 9$ ) and could be interesting for the adaptation of cultivars to low $\mathrm{N}$ fertilization. These QTLs need to be validated in other experiments because they were only detected in 1 year of the trial.

When considering all the $\mathrm{N}$ conditions together, 55 QTLs were specific to 1 year, two were common to 2 years and only DTF-QTLs were common to all years. Despite the fact that the 3 years of trials were conducted within the same pedo-climatic area (oceanic climate, deep loamy soil), there may have been interactions between the QTLs and the years. Indeed, the climatic periods (autumn, winter, spring, and GFP) were substantially different from 1 year to another, with for example a mild winter in LR11 and cold spring periods in LR12 and LR13, which could have had an impact on yield and yield components and the determining QTLs. Many studies reported QTLs which could be detected in some environments but not in others in several species including rapeseed (Bernardo 2008; Shi et al. 2009), however, this does not mean that a significant QTL $\times$ environment interaction exists. Indeed, a higher value of error variance in an environment may lead to more trouble at detecting a QTL in that environment. Thus the genomic regions may not be reliable through a wide range of environments (Bernardo 2008).

Possible applications in plant breeding programs

Although our results still require further validation, they could already provide some clues for breeding strategies to improve OSR adaptation to low $\mathrm{N}$ inputs. The question of the efficiency of indirect versus direct selection under stressed environments has led to contradictory results in other studies depending on the species and the experimental conditions (Brancourt-Hulmel et al. 2005). Bänziger et al. (1997) showed that the genetic correlation between high $\mathrm{N}$ and low $\mathrm{N}$ condition for seed yield in maize increased with decreasing $\mathrm{N}$ stress intensity. In our experimental conditions, the low $\mathrm{G} \times \mathrm{N}$ interaction effects, the low number of N-responsive QTLs as well as the high heritability values of the traits suggested a high genetic correlation between the two $\mathrm{N}$ conditions, leading to a similar efficiency of direct versus indirect selection. In addition, our results demonstrated that many yieldrelated loci were not controlled by plant developmental loci such as flowering time, which opens the way to marker assisted selection (MAS).

MAS programs have increased dramatically in plant breeding since the late 1980s. Those programs concerned essentially traits controlled by a few genes with major effects and which were directly introgressed in the new varieties by marker assisted backcross for example. For complex quantitative traits like yield, the strategy used is to enrich the population with the desired alleles of the targeted QTLs through marker assisted recurrent selection (Bernardo 2008). However, to date, only a few programs were successful compared to the number of linkage analyses published (Bernardo 2008). To be successful, a MAS program should involve traits with high heritability values and include QTLs accounting for a large proportion of the variance.

In the case of a complex trait controlled by many QTLs such as yield, the ideal goal is to pyramid several QTLs of interest into a single cultivar. Depending on the strategy, the breeder might prefer to generate varieties adapted to a large set of growing environments or on the contrary adapted to specific climatic/stress conditions. On the one hand, to ensure yield stability over the years in Le Rheu site, $R$ - $A 5$ associated with $R-C 1-a$ would be good candidate regions. Indeed, $R-A 5$ was a strong yield-related region (average $\mathrm{R}^{2}$ value of $23.1 \%$ with Montego as the favorable allele), stable across $\mathrm{N}$ and years, and RCl-a, comprised QTLs of oil found in the three years of trial in N1 or N2 (average $\mathrm{R}^{2}$ value of $12.1 \%$ with Montego as the favorable allele). On the other hand, the genomic regions controlling yield traits that were specific to one year of trial could also be exploited to confer adaptability to a wider range of climatic variations as occurred during our sets of trials. Hence, as $R-C 1-b, R-C 3-a, R-C 3-b$ and $R-C 8$ were specific to LR13 (Montego as the favorable allele), LR11 (Aviso as the favorable allele), LR13 (Montego as the favorable allele) and LR12 (Montego as the favorable allele) respectively, they could be used in this strategy. However, before using these QTLs for MAS, we need to reduce their confidence intervals and validate 
them in different genetic backgrounds, for instance using association mapping methods and by testing them in elite lines.

\section{Conclusion}

In a context of reducing inputs in agriculture, there is a huge need for breeding new $\mathrm{N}$ efficient rapeseed varieties. The objective would be to introduce genomic regions involved in NUE under low $\mathrm{N}$ fertilization conditions in the new varieties. Our study did not highlight QTLs specific to low N conditions; however, 11 regions were found to be stable across $\mathrm{N}$ conditions and/or years of trial and could be used for further studies. $R-A 5$ is of particular interest as a dense QTL area which was consistent in both $\mathrm{N}$ conditions and two out of the three sites. This region could be a good candidate for introducing stable seed yield and oil yield traits into rapeseed varieties in a breeding program.

Acknowledgments The authors are grateful to all the members of the Brassica group from INRA Le Rheu (France), especially Elise Alix, Solenn Guichard, Bernard Moulin and Bertrand Monnerie for their support in experimental trials, Cécile Baron and Laure Berton for their help in genotyping, Sophie Rolland and Françoise Leprince for the NIRS analyses. The authors would like to thank all the technical team of the Experimental Unit "La Motte" (INRA, UE30787, Le Rheu, France) for excellent management of the experimental trials as well as Sylvain Busnot and Béatrice Trinkler-Blaize from INRA Rennes (UMR SAS, Rennes, France) for the plant and soil N measurements. Thomas Foubert (Euralis Semences, France) is acknowledged for the production and the kind gift of the "Aviso $\times$ Montego" doubled haploid population. This work was supported by the "Agence Nationale de la Recherche - The French National Agency" (project ANR07-GPLA-016 "GENERGY") and by the program "Investments for the Future" (project ANR-11-BTBR-0004 "RAPSODYN"). A-S.B. is the recipient of a 3-year $\mathrm{PhD}$ fellowship from the Ministère de l'Enseignement Supérieur et de la Recherche.

Open Access This article is distributed under the terms of the Creative Commons Attribution License which permits any use, distribution, and reproduction in any medium, provided the original author(s) and the source are credited.

\section{References}

Asghari A, Mohammadi SA, Moghaddam M, Mohammaddoost HR (2007) QTL analysis for cold resistance-related traits in
Brassica napus using RAPD markers. J Food Agric Environ 5(3\&4): 188-192

Bänziger M, Betrán FJ, Lafitte HR (1997) Efficiency of highnitrogen selection environments for improving maize for low-nitrogen target environments. Crop Sci 37:1103-1109

Basunanda P, Radoev M, Ecke W, Friedt W, Becker HC, Snowdon RJ (2010) Comparative mapping of quantitative trait loci involved in heterosis for seedling and yield traits in oilseed rape (Brassica napus L.). Theor Appl Genet 120(2):271-281. doi:10.1007/s00122-009-1133-z

Bates D, Maechler M, Bolker B, Walker S (2013) lme4: linear mixed-effects models using Eigen and S4. R package version 1.0-4. http://CRAN.R-project.org/package=lme4

Bernardo R (2008) Molecular markers and selection for complex traits in plants: learning from the last 20 years. Crop Sci 48(5):1649. doi:10.2135/cropsci2008.03.0131

Berry PM, Spink J, Foulkes MJ, White PJ (2010) The physiological basis of genotypic differences in nitrogen use efficiency in oilseed rape (Brassica napus L.). Field Crop Res 119(2-3):365-373. doi:10.1016/j.fcr.2010.08.004

Brancourt-Hulmel M, Heumez E, Pluchard P, Beghin D, Depatureaux C, Giraud A, Le Gouis J (2005) Indirect versus direct selection of winter wheat for low-input or high-input levels. Crop Sci 45(4):1427. doi:10.2135/cropsci2003.0343

Broman KW, Wu H, Sen S, Churchill GA (2003) R/qtl: QTL mapping in experimental crosses. Bioinformatics 19:889-890

Burns MJ, Barnes SR, Bowman JG, Clarke MH, Werner CP, Kearsey MJ (2003) QTL analysis of an intervarietal set of substitution lines in Brassica napus: (i) seed oil content and fatty acid composition. Heredity 90(1):39-48. doi:10. 1038/sj.hdy.6800176

Campbell BT, Baenziger PS, Gill KS, Kent ME, Budak H (2003) Identification of QTLs and environmental interactions associated with agronomic traits on chromosome $3 \mathrm{~A}$ of wheat. Crop Sci 43:1493-1505

CETIOM (2011) Colza. http://www.cetiom.fr

Chen G, Geng J, Rahman M, Liu X, Tu J, Fu T, Li G, McVetty PBE, Tahir M (2010) Identification of QTL for oil content, seed yield, and flowering time in oilseed rape (Brassica napus). Euphytica 175(2):161-174. doi:10.1007/s10681010-0144-9

Cho Y-I, Jiang W, Chin J-H, Piao Z, Cho Y-G, McCouch SR, Koh H-J (2007) Identification of QTLs associated with physiological nitrogen use efficiency in rice. Mol Cell 23(1):72-79

Colnenne C, Meynard JM, Reau R, Justes E, Merrien A (1998) Determination of a critical dilution curve for winter oilseed rape. Ann Bot 81:311-317

Coque M, Martin A, Veyrieras JB, Hirel B, Gallais A (2008) Genetic variation for N-remobilization and postsilking $\mathrm{N}$-uptake in a set of maize recombinant inbred lines. 3 . QTL detection and coincidences. Theor Appl Genet 117(5):729-747. doi:10.1007/s00122-008-0815-2

Delourme R, Falentin C, Huteau V, Clouet V, Horvais R, Gandon B, Specel S, Hanneton L, Dheu JE, Deschamps M, Margale E, Vincourt P, Renard M (2006) Genetic control of oil content in oilseed rape (Brassica napus L.). Theor Appl Genet 113(7):1331-1345. doi:10.1007/s00122-0060386-z 
Delourme R, Falentin C, Fomeju BF, Boillot M, Lassalle G, Andre I, Duarte J, Gauthier V, Lucante N, Marty A, Pauchon M, Pichon JP, Ribiere N, Trotoux G, Blanchard P, Riviere N, Martinant JP, Pauquet J (2013) High-density SNP-based genetic map development and linkage disequilibrium assessment in Brassica napus L. BMC Genomics 14:120. doi:10.1186/1471-2164-14-120

Diepenbrock W (2000) Yield analysis of winter oilseed rape (Brassica napus L.): a review. Field Crop Res 67:35-49

Ding G, Zhao Z, Liao Y, Hu Y, Shi L, Long Y, Xu F (2012) Quantitative trait loci for seed yield and yield-related traits, and their responses to reduced phosphorus supply in Brassica napus. Ann Bot 109(4):747-759. doi:10.1093/ aob/mcr323

Ecke W, Uzunova M, Weissleder K (1995) Mapping the genome of rapeseed (Brassica napus L.) II.localization of genes controlling erucic acid synthetis and seed oil content. Theor Appl Genet 91:972-977

Fan C, Cai G, Qin J, Li Q, Yang M, Wu J, Fu T, Liu K, Zhou Y (2010) Mapping of quantitative trait loci and development of allele-specific markers for seed weight in Brassica napus. Theor Appl Genet 121(7):1289-1301. doi:10.1007/ s00122-010-1388-4

FAOSTAT (2012) Rapeseed statistics. http://faostat.fao.org

Good AG, Johnson SJ, De Pauw M, Carroll RT, Savidov N, Vidmar J, Lu Z, Taylor G, Stroeher V (2007) Engineering nitrogen use efficiency with alanine aminotransferase. Can J Bot 85(3):252-262. doi:10.1139/b07-019

Gorny AG, Sodkiewicz T (2001) Genetic analysis of the nitrogen and phosphorous utilization efficiencies in mature spring barley plants. Plant Breed 120:129-132

Gül MK (2002) QTL mapping and analysis of QTL $\times$ nitrogen interactions for some yield components in Brassica napus. Turk J Agric For 27:71-76

Gül MK, Becker H, Ecke W (2003) QTL mapping and analysis of QTL $\times$ nitrogen interactions for protein and oil contents in Brassica napus L. 11th international rapeseed congress. Denmark, Copenhagen, pp 91-93

Habash DZ, Bernard S, Schondelmaier J, Weyen J, Quarrie SA (2007) The genetics of nitrogen use in hexaploid wheat: N utilisation, development and yield. Theor Appl Genet 114(3):403-419. doi:10.1007/s00122-006-0429-5

Hirel B, Bertin P, Quillere I, Bourdoncle W, Attagnant C, Dellay C, Gouy A, Cadiou S, Retailliau C, Falque M, Gallais A (2001) Towards a better understanding of the genetic and physiological basis for nitrogen use efficiency in maize. Plant Physiol 125:1258-1270

Hirel B, Tétu T, Lea PJ, Dubois F (2011) Improving nitrogen use efficiency in crops for sustainable agriculture. Sustainability 3(9):1452-1485. doi:10.3390/su3091452

Honsdorf N, Becker HC, Ecke W (2010) Association mapping for phenological, morphological, and quality traits in canola quality winter rapeseed (Brassica napus L.). Genome 53(11):899-907. doi:10.1139/G10-049

Jeuffroy M-H, Valentin-Morison M, Champolivier L, Reau R (2006) Azote, rendement, et qualité des graines: mise au point et utilisation du modèle Azodyn-Colza pour améliorer les performances du colza vis-à-vis de l'azote. OCL 13(6):388-392. doi:10.1684/ocl.2006.0090

Kessel B, Schierholt A, Becker HC (2012) Nitrogen use efficiency in a genetically diverse set of winter oilseed rape
(L.). Crop Sci 52(6):2546. doi:10.2135/cropsci2012.02. 0134

Kjaer B, Jensen J (1995) The inheritance of nitrogen and phosphorous content in barley analysed by genetic markers. Hereditas 123:109-119

Kjeldahl JGC (1883) A new method for the determination of nitrogen in organic matter. Fresenius $\mathrm{J}$ Anal Chem 22:366-372

Kole C, Thormann CE, Karlsson BH, Palta JP, Gaffney P, Yandell B, Osborn TC (2002) Comparative mapping of loci controlling winter survival and related traits in oilseed Brassica rapa and B. napus. Mol Breed 9(3):201-210

Lancashire PD, Bleiholder H, Boom TVD, Langelüddeke P, Stauss R, Weber E, Witzenberger A (1991) A uniform decimal code for growth stages of crops and weeds. Ann Appl Biol 119:561-601. doi:10.1111/j.1744-7348.1991. tb04895.x

Laperche A, Brancourt-Hulmel M, Heumez E, Gardet O, Hanocq E, Devienne-Barret F, Le Gouis J (2007) Using genotype $\times$ nitrogen interaction variables to evaluate the QTL involved in wheat tolerance to nitrogen constraints. Theor Appl Genet 115(3):399-415. doi:10.1007/s00122007-0575-4

Lian X, Xing Y, Yan H, Xu C, Li X, Zhang Q (2005) QTLs for low nitrogen tolerance at seedling stage identified using a recombinant inbred line population derived from an elite rice hybrid. Theor Appl Genet 112(1):85-96. doi:10.1007/ s00122-005-0108-y

Liu X, Guo L, You J, Liu X, He Y, Yuan J, Liu G, Feng Z (2010) Progress of segregation distortion in genetic mapping of plants. Res J Agron 4(4):78-83

Mei DS, Wang HZ, Hu Q, Li YD, Xu YS, Li YC (2009) QTL analysis on plant height and flowering time in Brassica napus. Plant Breed 128(5):429-540

Merrien A, Landé N (2009) Rencontres techniques du colza: Physiologie du colza: mise en place du rendement. CETIOM

Mickelson S, See D, Meyer FD, Garner JP, Foster CR, Blake TK, Fischer AM (2003) Mapping of QTL associated with nitrogen storage and remobilization in barley (Hordeum vulgare L.) leaves. J Exp Bot 54(383):801-812

Miro B (2010) Identification of traits for nitrogen use efficiency in oilseed rape (Brassica napus L.). Newcastle University, Newcastle

Moll RH, Kamprath EJ, Jackson WA (1982) Analysis and interpretation of factors which contribute to efficiency of nitrogen utilization. Agron J 74:562-564

Mosier AR (2002) Environmental challenges associated with needed increases in global nitrogen fixation. Nutr $\mathrm{Cycl}$ Agroecosyst 63(2-3):101-116

Parnaudeau V, Jeuffroy MH, Machet JM, Reau R, Bissuel C, Eveillard P (2009) Methods for determining the nitrogen fertiliser requirements of some major arable crops in France, vol 661. IFS, Cambridge, pp 1-26

Qiu D, Morgan C, Shi J, Long Y, Liu J, Li R, Zhuang X, Wang Y, Tan X, Dietrich E, Weihmann T, Everett C, Vanstraelen S, Beckett P, Fraser F, Trick M, Barnes S, Wilmer J, Schmidt R, Li J, Li D, Meng J, Bancroft I (2006) A comparative linkage map of oilseed rape and its use for QTL analysis of seed oil and erucic acid content. Theor Appl Genet 114(1):67-80. doi:10.1007/s00122-006-0411-2 
Radoev M, Becker HC, Ecke W (2008) Genetic analysis of heterosis for yield and yield components in rapeseed (Brassica napus L.) by quantitative trait locus mapping. Genetics 179(3):1547-1558. doi:10.1534/genetics.108. 089680

Rathke G, Behrens T, Diepenbrock W (2006) Integrated nitrogen management strategies to improve seed yield, oil content and nitrogen efficiency of winter oilseed rape (Brassica napus L.): a review. Agric Ecosyst Environ 117(2-3):80-108. doi:10.1016/j.agee.2006.04.006

RCoreTeam (2013) R: a language and environment for statistical computing. Vienna, Austria

Rémy JC, Hébert J (1977) Le devenir des engrais azotés dans le sol, vol 63. Académies de l'Agriculture de, France

Schulte auf'm Erley G, Wijaya K-A, Ulas A, Becker H, Wiesler F, Horst WJ (2007) Leaf senescence and N uptake parameters as selection traits for nitrogen efficiency of oilseed rape cultivars. Physiol Plant 130(4):519-531. doi:10.1111/j.1399-3054.2007.00921.x

Schulte auf'm Erley G, Behrens T, Ulas A, Wiesler F, Horst WJ (2011) Agronomic traits contributing to nitrogen efficiency of winter oilseed rape cultivars. Field Crop Res 124(1):114-123. doi:10.1016/j.fcr.2011.06.009

Shi J, Li R, Qiu D, Jiang C, Long Y, Morgan C, Bancroft I, Zhao J, Meng J (2009) Unraveling the complex trait of crop yield with quantitative trait loci mapping in Brassica napus. Genetics 182(3):851-861. doi:10.1534/genetics.109. 101642

Slafer GA (2003) Genetic basis of yield as viewed from a crop physiologist's perspective. Ann Appl Biol 142:117-128

Tadege M, Sheldon CC, Helliwel CA, Stoutjesdijk P, Dennis ES, Peacock WJ (2001) Control of flowering time by FLC orthologues in Brassica napus. Plant J 28(5):545-553

Udall JA, Quijada PA, Lambert B, Osborn TC (2006) Quantitative trait analysis of seed yield and other complex traits in hybrid spring rapeseed (Brassica napus L.): 2. Identification of alleles from unadapted germplasm. Theor Appl Genet 113(4):597-609. doi:10.1007/s00122-006-0324-0

Vales MI, Schön CC, Capettini F, Chen XM, Corey AE, Mather DE, Mundt CC, Richardson KL, Sandoval-Islas JS, Utz
HF, Hayes PM (2005) Effect of population size on the estimation of QTL: a test using resistance to barley stripe rust. Theor Appl Genet 111:1260-1270. doi:10.1007/ s00122-0050043-y

Wei D, Cui K, Pan J, Wang Q, Wang K, Zhang X, Xiang J, Nie L, Huang J (2012) Identification of quantitative trait loci for grain yield and its components in response to low nitrogen application in rice. Aust J Agric Res 6(6):986-994

Xu F, Wang YH, Meng J (2001) Mapping boron efficiency gene(s) in Brassica napus using RFLP and AFLP markers. Plant Breed 120:319-324

Yang M, Ding G, Shi L, Feng J, Xu F, Meng J (2010) Quantitative trait loci for root morphology in response to low phosphorus stress in Brassica napus. Theor Appl Genet 121(1):181-193

Yau SK, Thurling N (1987) Genetic variation in nitrogen uptake and utilization in spring rape (Brassica napus L.) and its exploitation through selection. Plant Breed 98(4):330-338

Zhang L, Wang S, Li H, Deng Q, Zheng A, Li S, Li P, Li Z, Wang J (2010) Effects of missing marker and segregation distortion on QTL mapping in F2 populations. Theor Appl Genet 121(6):1071-1082. doi:10.1007/s00122-010-1372-Z

Zhao J, Becker HC, Zhang D, Zhang Y, Ecke W (2006) Conditional QTL mapping of oil content in rapeseed with respect to protein content and traits related to plant development and grain yield. Theor Appl Genet 113(1):33-38. doi:10.1007/s00122-006-0267-5

Zhao J, Huang J, Chen F, Xu F, Ni X, Xu H, Wang Y, Jiang C, Wang H, Xu A, Huang R, Li D, Meng J (2012) Molecular mapping of Arabidopsis thaliana lipid-related orthologous genes in Brassica napus. Theor Appl Genet 124(2):407-421. doi:10.1007/s00122-011-1716-3

Zou J, Jiang C, Cao Z, Li R, Long Y, Chen S, Meng J (2010) Association mapping of seed oil content in Brassica napus and comparison with quantitative trait loci identified from linkage mapping. Genome 53(11):908-916. doi:10.1139/ G10-075 